Article

\title{
Survival Strategies of Streptococcus pyogenes in Response to Phage Infection
}

\author{
Dior Beerens ${ }^{1,2}$, Sandra Franch-Arroyo ${ }^{1,2}$, Timothy J. Sullivan ${ }^{1,+}$, Christian Goosmann ${ }^{3}$, Volker Brinkmann ${ }^{3}$ and \\ Emmanuelle Charpentier ${ }^{1,2, *}$
}

1 Max Planck Unit for the Science of Pathogens, 10117 Berlin, Germany; beerens@mpusp.mpg.de (D.B.); arroyo@mpusp.mpg.de (S.F.-A.); Timothy.J.Sullivan@darthmouth.edu (T.J.S.)

2 Institute for Biology, Faculty of Life Sciences, Humboldt University Berlin, 10115 Berlin, Germany

3 Core Facility Microscopy, Max Planck Institute for Infection Biology, 10117 Berlin, Germany; goosmann@mpiib-berlin.mpg.de (C.G.); brinkmann@mpiib-berlin.mpg.de (V.B.)

* Correspondence: research-charpentier@mpusp.mpg.de

+ Current address: Department of Biomedical Data Science, Dartmouth College, Hanover, NH 03775, USA.

check for updates

Citation: Beerens, D.; Franch-Arroyo, S.; Sullivan, T.J.; Goosmann, C.; Brinkmann, V.; Charpentier, E. Survival Strategies of Streptococcus pyogenes in Response to Phage Infection. Viruses 2021, 13, 612. https://doi.org/10.3390/v13040612

Academic Editors:

Zuzanna Drulis-Kawa and Daria Augustyniak

Received: 3 March 2021

Accepted: 28 March 2021

Published: 2 April 2021

Publisher's Note: MDPI stays neutral with regard to jurisdictional claims in published maps and institutional affiliations.

Copyright: (c) 2021 by the authors. Licensee MDPI, Basel, Switzerland. This article is an open access article distributed under the terms and conditions of the Creative Commons Attribution (CC BY) license (https:// creativecommons.org/licenses/by/ $4.0 /)$.

\begin{abstract}
Bacteriophages exert strong evolutionary pressure on their microbial hosts. In their lytic lifecycle, complete bacterial subpopulations are utilized as hosts for bacteriophage replication. However, during their lysogenic lifecycle, bacteriophages can integrate into the host chromosome and alter the host's genomic make-up, possibly resulting in evolutionary important adjustments. Not surprisingly, bacteria have evolved sophisticated immune systems to protect against phage infection. Streptococcus pyogenes isolates are frequently lysogenic and their prophages have been shown to be major contributors to the virulence of this pathogen. Most S. pyogenes phage research has focused on genomic prophages in relation to virulence, but little is known about the defensive arsenal of $S$. pyogenes against lytic phage infection. Here, we characterized Phage A1, an S. pyogenes bacteriophage, and investigated several mechanisms that S. pyogenes utilizes to protect itself against phage predation. We show that Phage A1 belongs to the Siphoviridae family and contains a circular double-stranded DNA genome that follows a modular organization described for other streptococcal phages. After infection, the Phage A1 genome can be detected in isolated S. pyogenes survivor strains, which enables the survival of the bacterial host and Phage A1 resistance. Furthermore, we demonstrate that the type II-A CRISPR-Cas system of S. pyogenes acquires new spacers upon phage infection, which are increasingly detectable in the absence of a capsule. Lastly, we show that $S$. pyogenes produces membrane vesicles that bind to phages, thereby limiting the pool of phages available for infection. Altogether, this work provides novel insight into survival strategies employed by S. pyogenes to combat phage predation.
\end{abstract}

Keywords: Streptococcus pyogenes; bacteriophage defense; Phage A1; CRISPR-Cas; membrane vesicles; capsule

\section{Introduction}

The so-called "flesh-eating bacterium" Streptococcus pyogenes is a Gram-positive $\beta$ hemolytic pathogen that strictly infects humans in natural settings [1,2]. Although S. pyogenes can colonize the throat and skin asymptomatically [3], the hallmark of S. pyogenes is its ability to cause a vast variety of diseases [4]. Clinical manifestations of S. pyogenesinfections range from superficial skin infections and pharyngitis to toxin-mediated diseases (e.g., streptococcal toxic shock syndrome (STSS)), and invasive disease in subcutaneous tissues [5].

With an estimated 616 million pharyngitis cases, almost 2 million severe S. pyogenes disease cases and more than 500,000 deaths per year, S. pyogenes remains among the top 10 individual pathogens causing morbidity and mortality [6]. To date, S. pyogenes has remained universally susceptible to penicillin, which remains the drug of choice to treat 
pharyngeal infections as well as for complicated or invasive infections [7]. Although no penicillin-resistant $S$. pyogenes strains have been observed in clinical settings, up to $40 \%$ treatment failure of severe $S$. pyogenes-associated disease with these antibiotics has been reported [8]. These high mortality and treatment failure rates-despite the use of adequate antimicrobials-call for effective alternatives. One alternative to antibiotics that has recently gained an increasing momentum is phage therapy [9]. However, bacteriophages are known to play important roles in the shaping of bacterial populations as well as the dissemination of bacterial genetic material to new strains, potentially resulting in the spread of virulence factors and antibiotic resistance genes [10].

The $\mathrm{M}$ protein is considered a major virulence determinant for S. pyogenes [11], since emm gene knock-out $(\mathrm{KO})$ mutants are neither able to survive in mouse models nor in human phagocyte-containing blood [12,13]. Additionally, M protein hyperproduction inhibits phage adsorption, which results in phage-resistant S. pyogenes mutants [14], suggesting that the $\mathrm{M}$ protein could serve a dual function in both phage and phagocyte resistance. Another important virulence factor of $S$. pyogenes is the hyaluronic acid (HA) capsule, which is chemically identical to HA produced by mammalian tissues [15]. This molecular mimicry between the bacterial surface and host molecules reduces the ability of the host immune system to detect and kill S. pyogenes. Indeed, encapsulated S. pyogenes strains are associated with more severe disease [16] and were shown to be more resistant to neutrophilmediated killing in mice [17]. Early studies have also shown that enzymatic removal of the HA capsule increased phage infectivity, suggesting that it provides a barrier between bacteriophages and their bacterial surface-based receptor [18]. The biosynthesis of the HA capsule is regulated by the has $A B C$ operon [19], but only HasA and HasB are required for the production of the HA capsule [20]. The has $A B C$ operon is regulated by the Control of Virulence (CovRS) two-component system [21], and spontaneous mutations within covRS result in highly encapsulated and invasive S. pyogenes strains [22].

S. pyogenes isolates are frequently lysogenic, and most $S$. pyogenes phage research has focused on genomic prophages in relation to horizontal gene transfer (HGT) and virulence, but surprisingly little is known about the interplay between $S$. pyogenes and its lytic phages [23]. The few reported lytic phages include Phage A1, A6, A12, A25 and A27; however, only Phage A25 has been studied in detail to date [18,24,25]. Phage A25 belongs to the Siphoviridae family [26], with low burst sizes ranging from 12 to 32 plaque-forming units (PFUs) per infected cell depending on the host strain $[27,28]$. Host recognition is thought to be a two-step process, as peptidoglycan was shown to be the cell receptor for Phage A25 that mediated reversible adsorption, but an unknown additional factor is required for irreversible binding and DNA injection [29]. Lytic S. pyogenes Phages A6, A12, A25 and A27 have a broad host range and are able to infect some strains of Group C Streptococci (GCS), and Phage A25 was shown to be adaptable to Group G Streptococci (GGS) $[25,29]$. Recently, the genome sequence of Phage A25 has been determined to be $33,900 \mathrm{bp}$ in size with a GC content of $38.44 \%$ [30]. The phages of S. pyogenes comprise a modular genetic arrangement with regions dedicated to gene regulation, DNA replication, DNA cleavage, DNA packaging, capsid and tail morphogenesis and lysis. In contrast to most prophages of S. pyogenes, however, no identifiable virulence genes were found in the genome of Phage A25 [30]. Genomic analysis of the Phage A25 and prophage genomes provided hints towards the broad host range of $S$. pyogenes phages. A highly mosaic nature of these genomes was identified, and genetic modules were shown to be shared between phages of S. pyogenes, Streptococcus pneumoniae and Streptococcus suis, among others [30].

In this study, we demonstrate that Phage A1 is not a strictly lytic phage as previously reported and we shed light on immune strategies of S. pyogenes to withstand phage infection. We observe that membrane vesicles (MVs) produced by S. pyogenes are able to scavenge phages from the environment and reduce the infection pressure. Additionally, $S$. pyogenes produces a hyaluronic acid capsule that prevents phages to bind to their receptor. Interestingly, CRISPR-Cas-mediated spacer acquisition is increased in the absence of the capsule. In a minor fraction of infected cells, the Phage A1 genome is detectable in the $S$. 
pyogenes genome, which enables the survival of the bacterial host. Phage A1-surviving clones neither become more virulent than their WT counterpart in vitro nor develop ampicillin tolerance. Together, our results highlight the complex interplay between streptococcal phages and their hosts, and provide insight into a potential role for streptococcal phages or phage-derived products for the treatment of severe infections.

\section{Materials and Methods}

\subsection{Bacterial Strains}

The bacterial strains used in this study are listed in Table 1. S. pyogenes strains were grown in either Todd Hewitt Broth (THB) or Brain Heart Infusion broth (BHI) without shaking at $37{ }^{\circ} \mathrm{C}$ and $5 \% \mathrm{CO}_{2}$. TSA blood agar (TrypticaseTM Soy Agar, Becton Dickinson, Heidelberg, Germany) supplemented with 3\% defibrinated sheep blood (Xebios Diagnostics, Düsseldorf, Germany) was used for cultivation on solid medium.

Table 1. S. pyogenes strains used in this study.

\begin{tabular}{|c|c|c|}
\hline Strain & Description & Origin \\
\hline ATCC 12202 & $\begin{array}{c}\text { Streptococcus pyogenes Rosenbach } \\
\left(\text { ATCC }^{\circledR} 12202^{\mathrm{TM}}\right)\end{array}$ & ATCC database \\
\hline SF370 & 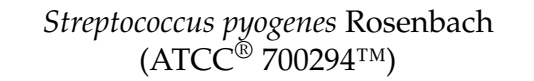 & $\begin{array}{c}\text { Ferretti et al. } 2001 \text { [31] and Abbot } \\
\text { et al. } 2007 \text { [32] }\end{array}$ \\
\hline SF370 $\Delta$ has $A$ & $\begin{array}{l}\text { SF370 with complete deletion of the } \\
\text { has } A \text { coding sequence }\end{array}$ & Abbot et al. 2007 [32] \\
\hline 5448 & $\begin{array}{l}\text { Wild-type clinical STSS/Necrotizing } \\
\text { Fasciitis isolate }\end{array}$ & $\begin{array}{l}\text { M. Walker, University of } \\
\text { Queensland, Australia [33] }\end{array}$ \\
\hline 5448AP & $\begin{array}{l}\text { Animal passaged variant of } 5448 \\
\text { containing a 1-bp insertion in covS }\end{array}$ & $\begin{array}{l}\text { M. Walker, University of } \\
\text { Queensland, Australia [34] }\end{array}$ \\
\hline ISS3348 & Clinical isolate; $30-b p$ deletion in covs & G. Teti, University of Messina, Italy \\
\hline $3348 \Delta$ has $A$ & $\begin{array}{l}\text { ISS3348 with complete deletion of the } \\
\text { has } A \text { coding sequence }\end{array}$ & Resch et al. 2016 [35] \\
\hline
\end{tabular}

\subsection{Phage Propagation}

S. pyogenes ATCC 12202 was grown overnight and diluted 1:100 into $25 \mathrm{~mL}$ of fresh pre-warmed THB and incubated at $37^{\circ} \mathrm{C}$ until mid-logarithmic phase $\left(\mathrm{OD}_{600 \mathrm{~nm}}=0.25\right)$ was reached. At this point, $\mathrm{CaCl}_{2}$ was added to the culture to reach a final concentration of $10 \mathrm{mM}$. Phage A1 (ATCC 12202-B1) was added to achieve a final multiplicity of infection (MOI) of 0.1 . After $20 \mathrm{~min}$ of incubation at $30^{\circ} \mathrm{C}$, the complete solution was transferred into $100 \mathrm{~mL}$ fresh $10 \mathrm{mM} \mathrm{CaCl}_{2}$-containing THB and incubated for an additional $4 \mathrm{~h}$ at $37^{\circ} \mathrm{C}$. Solid $\mathrm{NaCl}$ was added to reach a final concentration of $1 \mathrm{M}$. The solution was stored overnight at $4{ }^{\circ} \mathrm{C}$ and subsequently spun for $10 \mathrm{~min}$ at $10000 \times g$ at $4{ }^{\circ} \mathrm{C}$ to pellet bacterial debris. The supernatant was filtered using a $0.22 \mu \mathrm{m}$ filter and subjected to ultracentrifugation for $2 \mathrm{~h}$ at $50000 \times g$ at $4^{\circ} \mathrm{C}$ (SW32 Ti rotor, Optima XPN-100 ultracentrifuge, Beckmann Coulter, Krefeld, Germany). The resulting pellet was resuspended in SM-buffer (100 mM $\mathrm{NaCl}, 8 \mathrm{mM} \mathrm{MgSO}_{4}, 50 \mathrm{mM}$ Tris- $\left.\mathrm{HCl}(\mathrm{pH} 7.5)\right)$ and stored at $4{ }^{\circ} \mathrm{C}$. Phage concentrations were determined by plaque assays on double-layer BHI plates.

\subsection{Bacteriophage A1-Membrane Vesicle Interaction Assays}

S. pyogenes MVs were purified from late-logarithmic phase cultures $\left(\mathrm{OD}_{600 \mathrm{~nm}}=0.4\right)$ according to a previously described method [35]. Briefly, bacterial cultures were centrifuged first $\left(9300 \times g, 10 \mathrm{~min}, 10^{\circ} \mathrm{C}\right)$, after which the supernatants were transferred to new tubes and centrifuged again to remove residual bacterial debris $(18600 \times g, 15 \mathrm{~min}$, $10^{\circ} \mathrm{C}$ ). Supernatants were filtered twice through $0.22 \mu \mathrm{m}$ pore polyethylsulfone (PES) membranes (Thermofisher scientific, Darmstadt, Germany) and spotted on TSA blood plates to confirm their sterility. These batches were centrifuged at $175,000 \times g$ for $4 \mathrm{~h}$ at $10{ }^{\circ} \mathrm{C}$ (Ti45 rotor, Optima XPN-100 ultracentrifuge, Beckmann Coulter). The resulting pellets were resuspended in $30 \mathrm{~mL}$ total volume phosphate-buffered saline (PBS) (Thermofisher 
scientific, Darmstadt, Germany), pooled, and centrifuged again at $175,000 \times g$ for $3 \mathrm{~h}$ at $10{ }^{\circ} \mathrm{C}$. The resulting pellet was resuspended in a final volume of $1 \mathrm{~mL}$ of PBS prior to quantification using Nanoparticle Tracking Analysis (NTA) (NS300, Malvern Panalytical, Kassel, Germany).

MVs were mixed with $10 \mu \mathrm{L}$ of Phage A1 in MOI ratios of 10, 1, 0.1:1000, respectively, and added to $80 \mu \mathrm{L} 10 \mathrm{mM} \mathrm{CaCl}_{2}$-containing THB. After $15 \mathrm{~min}$ of incubation, samples were analyzed by electron microscopy (EM) as described below or added to a mid-log culture of S. pyogenes strains SF370 $\left(\mathrm{OD}_{600 \mathrm{~nm}}=0.25\right)$ achieving a final MOI of 1 , of which $200 \mu \mathrm{L}$ was transferred into 96 -well plates. The $\mathrm{OD}_{600 \mathrm{~nm}}$ was measured at $37^{\circ} \mathrm{C}$ and $5 \%$ $\mathrm{CO}_{2}$ every $10 \mathrm{~min}$ for $4 \mathrm{~h}$ in a Synergy $\mathrm{H} 1$ microplate reader (BioTek, Bad Friedrichshall, Germany). A control consisted of MVs alone, where SM-buffer substituted phage samples were compared to pure phage infection. All experiments were performed in both technical and biological triplicates.

\subsection{Electron Microscopy and Image Analysis}

Overnight cultures of S. pyogenes ATCC 12202 or SF370 were diluted 1:100 in fresh THB medium and incubated until mid-logarithmic phase $\left(\mathrm{OD}_{600 \mathrm{~nm}}=0.25\right)$ was reached. $\mathrm{CaCl}_{2}$ was supplied to the culture to reach a final concentration of $10 \mathrm{mM}$. Phage A1 was added to achieve an MOI of 10 and fixed with 2.5\% glutaraldehyde (GA) 5, 15, 25, 45, 60 and 90 min post-infection. For scanning electron microscopy (SEM), bacteria were added directly onto poly-L-lysine-treated glass coverslips. The samples were post-fixed in $0.5 \%$ osmium-tetroxide, tannic acid and osmium-tetroxide again. The coverslips were then dehydrated in a graded ethanol series, dried in carbon dioxide at critical point and vacuum coated with $3 \mathrm{~nm}$ carbon-platinum. Imaging was performed using a LEO 1550 (Zeiss, Oberkochen, Germany) scanning electron microscope using an in-lens detector at $20 \mathrm{kV}$ acceleration voltage. For transmission electron microscopy (TEM), aliquots of phage or phage:MV samples were applied to fresh glow discharged carbon-film-coated copper grids and allowed to adsorb for $10 \mathrm{~min}$. After three washes with distilled water, the grids were contrasted with $4 \%$ phospho-tungstic-acid $/ 1 \%$ trehalose, touched on filter paper and air-dried. The grids were examined in a LEO 906 (Zeiss AG, Oberkochen, Germany) electron microscope operated at $100 \mathrm{kV}$ and images were recorded with a Morada digital camera (SIS-Olympus, Münster, Germany). Images were processed and analyzed with Fiji, an open source scientific image processing application (http:/ / fiji.sc (accessed on 2 April 2021)).

\subsection{One-Step Growth Analysis}

One-Step Growth Curves (OSGCs) were performed to determine the latency period and burst size of Phage A1 according to a previously described method [36]. Briefly, a mid-log $\left(\mathrm{OD}_{600 \mathrm{~nm}}=0.25\right)$ culture of S. pyogenes ATCC 12202 in $10 \mathrm{mM} \mathrm{CaCl}_{2}$-containing THB was infected with Phage A1 at an MOI of 1 and was allowed to adsorb for $10 \mathrm{~min}$ at $37^{\circ} \mathrm{C}$. The infected culture was centrifuged $(4000 \times g$ for $3 \mathrm{~min}$ at RT, Heraeus Multifuge $\mathrm{X} 3 \mathrm{R}$, Thermo Scientific) to remove not adsorbed phages and the pellet was resuspended in $10 \mathrm{~mL}$ of pre-warmed $10 \mathrm{mM} \mathrm{CaCl}_{2}$-containing THB. A total of $100 \mu \mathrm{L}$ of this culture was transferred into $9.9 \mathrm{~mL}$ of fresh $10 \mathrm{mM} \mathrm{CaCl}_{2}$-containing THB and gently mixed. A 10-fold serial dilution of this mixture was prepared twice and incubated at $37^{\circ} \mathrm{C}$ and $5 \%$ $\mathrm{CO}_{2}$. Then, $100 \mu \mathrm{L}$ samples were collected every 5-10 min (depending on the growth phase identified by initial trials) from each flask for PFU determination by plaque assays on double-layer BHI plates. S. pyogenes ATCC 12202 grown for $24 \mathrm{~h}$ in BHI served as plating host. Plates were incubated at $37{ }^{\circ} \mathrm{C}$ and $5 \% \mathrm{CO}_{2}$ overnight. Burst size was calculated by dividing the average PFU after phage burst by the average amount of infection centers in the latent phase. The latent period was determined by the moment the first increase in $\mathrm{PFU} / \mathrm{mL}$ was observed. OSGCs were performed in biological triplicates. 


\subsection{Spectrophotometric Phage A1 Lysis Profile}

Overnight cultures of S. pyogenes were diluted 1:100 in fresh THB medium and incubated until mid-logarithmic phase $\left(\mathrm{OD}_{600 \mathrm{~nm}}=0.25\right)$ was reached. $\mathrm{CaCl}_{2}$ was added to the culture to reach a final concentration of $10 \mathrm{mM}$. In total, $180 \mu \mathrm{L}$ per condition was aliquoted in wells of a 96-well plate, and Phage A1 was added to achieve MOIs ranging from 1 to 0.001 , after which the $\mathrm{OD}_{600 \mathrm{~nm}}$ of each culture was measured at $37^{\circ} \mathrm{C}$ and $5 \% \mathrm{CO}_{2}$ every $10 \mathrm{~min}$ for $4 \mathrm{~h}$ in a Synergy H1 microplate reader (BioTek, Bad Friedrichshall, Germany). Averages and standard deviations are given for one out of three biological replicates in triplicate per strain.

\subsection{Phage A1 Efficiency of Plating on M1 Serotype S. pyogenes}

Efficiency of plaquing (EOP) assays were performed by spotting serial dilutions of Phage A1 onto M1 serotype S. pyogenes. Tested S. pyogenes strains were diluted 1:100 in fresh THB medium and incubated until mid-logarithmic phase $\left(\mathrm{OD}_{600 \mathrm{~nm}}=0.25\right)$ was reached. Hyaluronidase was added in a final concentration of $68 \mu \mathrm{g} / \mathrm{mL}$ when necessary. $\mathrm{CaCl}_{2}$ was added to the culture to reach a final concentration of $10 \mathrm{mM}$. A total of $250 \mu \mathrm{L}$ per culture was mixed with $4 \mathrm{~mL}$ of $10 \mathrm{mM} \mathrm{CaCl}_{2}$-containing $0.7 \% \mathrm{BHI}$ soft agar $\left(48^{\circ} \mathrm{C}\right)$ and directly poured onto pre-warmed BHI plates. After $15 \mathrm{~min}$ of solidification, $10 \mu \mathrm{L}$ of a 10-fold dilution series of Phage A1 was spotted onto the soft agar and allowed to soak into the agar for $15 \mathrm{~min}$. Plates were incubated overnight at $37^{\circ} \mathrm{C}$ and $5 \% \mathrm{CO}_{2}$. Counted plaques were converted to $\mathrm{PFU} / \mathrm{mL}$.

\subsection{Lysogeny and CRISPR Acquisition Testing}

S. pyogenes strains in mid-log phase were infected with Phage A1 at an MOI of 0.1 and were incubated at $37^{\circ} \mathrm{C}$ and $5 \% \mathrm{CO}_{2}$ for $24 \mathrm{~h}$. The pellet of $1 \mathrm{~mL}$ lysed culture was resuspended in $100 \mu \mathrm{L}$ fresh THB and plated on BA plates. After overnight growth, single colonies were selected, passaged twice in THB and tested for Phage A1 resistance. Phage resistance was examined by adding Phage A1 reaching MOIs of $0.1,1,10$ and 100 to a mid-log culture of lysogenized S. pyogenes strains in the presence of $\mathrm{Ca}^{2+}$. Infected cultures were incubated for $4 \mathrm{~h}$ at $37^{\circ} \mathrm{C}$ and $5 \% \mathrm{CO}_{2}$ and pictured. The genomic DNA of resistant colonies was subjected to PCR to screen for phage integration with primers specific to Phage A1 (5' GGGGGATAAAAATGAATGAAACGCT (F) and 5' TGCGGACACTGACAAAATTTTTGG (R1)) and primers that should not amplify an amplicon when the Phage DNA is integrated (5' GGGGGATAAAAATGAATGAAACGCT (F) and 5' CGAATTTAGGAAGTTAATTTAGG (R2)). Primers that amplify the leader proximal part of the CRISPR array until the first spacer already present in the native CRISPR array were used to investigate CRISPR acquisition (Fw: 5' GCTTTTCAAGACTGAAGTCTAGC and Rv: 5' GCGCAAGAAGAAATCAACCAG).

\subsection{Genomic DNA Isolation}

Phage A1 lysates were subjected to DNAse I ( $\mathrm{U} / \mathrm{mL}$ final concentration) and RNaseA $\left(100 \mu \mathrm{g} / \mathrm{mL}\right.$ final concentration) treatment for $30 \mathrm{~min}$ at $37^{\circ} \mathrm{C}$. EDTA was added to a final concentration of $5 \mathrm{mM}$, mixed and incubated for $10 \mathrm{~min}$ at $70^{\circ} \mathrm{C}$. Hereafter, genomic DNA from $10^{9}$ PFUs was extracted using a Phage DNA Isolation Kit according to the manufacturer's protocol (Norgen Biotek corp., Thorold, Canada). Genomic DNA from S. pyogenes was isolated using the NucleoSpin ${ }^{\circledR}$ Microbial DNA kit (Macherey-Nagel, Düren, Germany) and purified with a genomic DNA Clean \& Concentrator kit (Zymo research, Freiburg, Germany). Both Phage A1 and S. pyogenes DNA concentrations were determined by NanoDrop and DNA integrity was verified in a $0.7 \%$ agarose gel.

\subsection{Genome Sequencing and Bioinformatic Analysis}

A total of 750 ng of Phage A1 genomic DNA was used to generate the DNA library that was sequenced with 150 bp paired-ends using a NovaSeq 6000 system (Illumina Inc., San Diego, CA, USA). Whole Genome Sequencing (WGS) reads were trimmed using 
Trimmomatic [37] version 0.38 . Trimmomatic was supplied with the following parameters: \{ILLUMINACLIP:\$ADAPTORS:2:30:10 LEADING:3 TRAILING:3 SLIDINGWINDOW:4:15 MINLEN:25 HEADCROP:3\}, where \$ADAPTORS is a fasta file containing TruSeq adapters and the sequence of the PhiX sequencing control. Trimmed read fastq files were down sampled to 250,000 paired-end reads using the linux utility 'head $-\mathrm{n} 100000^{\prime}$. Contigs were assembled using Spades [38] version 3.12.0 in paired-end mode with default parameters. The resulting viral genome was annotated using Prokka [39] version 1.13.7. Prokka was supplied with the following parameters: \{-kingdom Viruses-proteins KT388093.1.gb-prefix phage\}. Remaining hypothetical proteins were manually investigated for homology using BlastP. Phage A1 genome accession number: MW495853.

\subsection{Phylogenetic Analysis}

Streptococcal phage genomes were downloaded from the NCBI database and phylogenetic studies based on whole phage genomes were performed using VICTOR [40]. All pairwise comparisons of the nucleotide sequences were conducted using the GenomeBLAST Distance Phylogeny (GBDP) method under settings recommended for prokaryotic viruses [40]. The branch lengths are scaled in terms of the GBDP distance formula $\mathrm{D}_{0}$ [40]. Branch support was inferred from 100 pseudo-bootstrap replicates each. Trees were rooted and visualized with FigTree v1.4.4.

\subsection{Cell Line Maintanance and Differentiation}

The B-cell Leukaemia C/EBP $\alpha$ (CCAAT-enhancer-binding protein $\underline{\alpha}$, where CCAAT stands for a Cytosine-Cytosine-Adenosine-Adenosine-Thymidine motif) Estrogen Receptor clone 1 cell line (BLaER1) [41] was kindly provided by Prof. Thomas Graf (Centre for Genomic Regulation, Barcelona). BLaER1 cells were maintained in RPMI medium supplemented with $1 \%$ L-Glutamine, $1 \%$ penicillin-streptomycin (P/S, Sigma-Aldrich, Darmstadt, Germany), 10\% FBS and 1\% sodium pyruvate (Thermofisher scientific, Darmstadt, Germany). BLaER1 cells were transdifferentiated into monocyte-like cells for 7 days in six-well plates by seeding $1 \times 10^{6}$ cells/well in $3 \mathrm{~mL}$ of medium supplemented with $10 \mathrm{ng} / \mathrm{mL}$ of human recombinant IL-3, $10 \mathrm{ng} / \mathrm{mL}$ of human recombinant Macrophage Colony-stimulating Factor 1 (both from PeproTech, Hamburg, Germany) and $100 \mathrm{nM}$ of $\beta$-Estradiol (Sigma-Aldrich, Darmstadt, Germany). Half of the medium was exchanged at days 2 and 5 for fresh medium containing identical supplements. On day 7 after differentiation, cells were harvested, counted with a CASY cell counter and cells were spun down $(500 \times g, 5 \mathrm{~min}, \mathrm{RT})$. Cell pellets were resuspended in an adjusted volume of fresh medium without cytokines or P/S at a final density of $1 \times 10^{6}$ cells $/ \mathrm{mL}$. Finally, $10^{6}$ cells were seeded per well in a 24-well plate for infection assays.

\subsection{Infection Assay}

S. pyogenes strains in late-log phase $\left(\mathrm{OD}_{600 \mathrm{~nm}}=0.4\right)$ were spun down $(6000 \times g, 3 \mathrm{~min}$, RT) and washed once with $1 \mathrm{~mL}$ of phosphate-buffered saline (PBS). Bacterial suspensions were passed 10 times through a 27 Gauge syringe insert (NeoLab, Heidelberg, Germany) in a $1 \mathrm{~mL}$ syringe (VWR) to separate the cocci chains, and $10^{6}$ BLaER1 cells were infected at MOI 1. Plates were centrifuged $(300 \times g, 5 \mathrm{~min}, \mathrm{RT})$ to synchronize the infection. P/S was added after $1 \mathrm{~h}$ to a final concentration of $1 \%$ to inhibit bacterial replication and excessive cell death. After overnight incubation, plates were centrifuged $(500 \times g, 5 \mathrm{~min}$, RT), after which supernatants were collected and stored at $-20^{\circ} \mathrm{C}$ until use. Supernatants were thawed on ice and IL- 6 and IL- $1 \beta$ concentrations were measured using EnzymeLinked ImmunoSorbent Assay (ELISA) kits (Thermofisher Scientific, Darmstadt, Germany) according to the manufacturer's protocol. ELISA data were analyzed by extrapolating values of each sample from the standard curve using a log-log fit. The standard curve was generated for each plate by plotting the logarithm of the absorbance of the standards against the logarithm of the concentrations of each standard. In contrast, fresh supernatants 
were used to measure cell death using the Lactate Dehydrogenase (LDH)-Cytotoxicity Assay Kit II (Abcam, Cambridge, UK) according to the manufacturer's instructions.

\subsection{Antibiotic Susceptibility}

The susceptibility of S. pyogenes and their lysogenized variants to the commonly used antibiotic ampicillin to treat $S$. pyogenes infections was tested. S. pyogenes strains were grown on BA plates and harvested in sterile PBS. S. pyogenes suspensions were set at $\sim 0.5 \mathrm{McF}$ arland and swabbed onto Mueller-Hinton II agar (MH-II) plates (Sigma-Aldrich, Darmstadt, Germany). Ampicillin E-tests (bestbion dx, Köln, Germany) were placed in the middle of the plate and plates were incubated overnight at $37{ }^{\circ} \mathrm{C}$ with $5 \% \mathrm{CO}_{2}$. The minimum inhibitory concentration (MIC) was determined after $24 \mathrm{~h}$.

\subsection{Statistics}

Paired $t$ tests or one-way ANOVA tests were performed for comparisons between data sets. All analyses were performed using Prism GraphPad software v8.0.0 (GraphPad software Inc., San Diego, CA, USA). $p<0.05$ was considered statistically significant.

\section{Results}

\subsection{Virion Morphology and Physiological Characterization of S. pyogenes Bacteriophage A1}

S. pyogenes Bacteriophage A1 (Phage A1) was obtained from the ATCC database and, after obtaining high titer phage stocks, the morphology of Phage A1 was investigated by both TEM and SEM. The obtained EM images revealed that Phage A1 virions have icosahedral heads and long non-contractile tails (Figure 1A,B), typical for the Siphoviridae family among the Caudovirales order. In total, 30 isolated phages in TEM images were measured to determine phage dimensions, which are summarized in Table 2. We continued with the investigation of the physiological properties of Phage A1. First, we examined the lysis profile of Phage A1 on S. pyogenes strain ATCC 12202 (Figure 1C). Phage A1 exhibited a strong lytic phenotype at MOI 1 and this lytic phenotype was still present at MOI 0.05 with rapid lysis of the culture occurring after $1.5 \mathrm{~h}$ of infection. However, we observed a clear delay in lysis or no lysis occurring at MOI 0.01 or lower. Additionally, cultures were not cleared after overnight incubation at lower MOIs starting from MOI 0.01. We performed one-step growth curves (OSGCs) to determine the lag phase and average number of newly produced phages per infected cell. Phage A1 showed a latent period of 40 min, after which the first increase in PFUs was observed. Additionally, the burst size of Phage A1 is approximately 31 PFUs per infected cell on strain ATCC 12202 (Figure 1D).

A

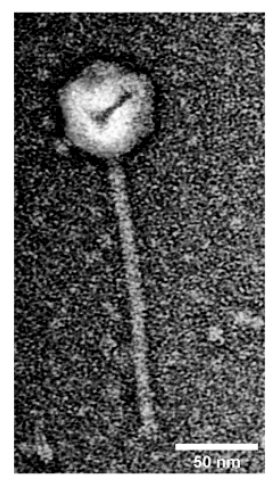

B

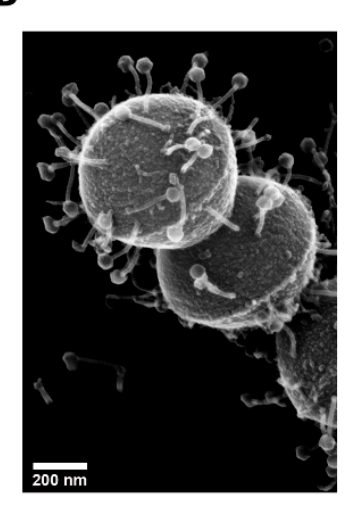

\section{C}

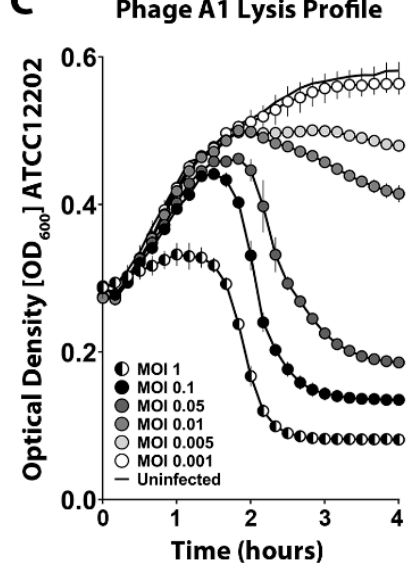

D

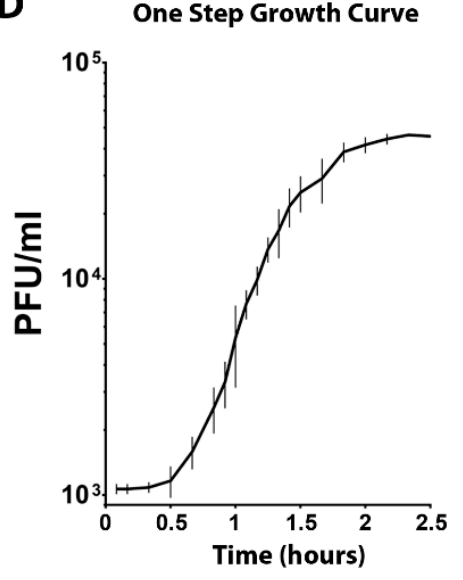

Figure 1. Phage A1 morphology and growth characteristics. (A) TEM micrograph of purified Phage A1; (B) SEM micrograph of Phage A1 bound to S. pyogenes ATCC 12202 at multiplicity of infection (MOI) 25 after 10 min of coincubation; (C) Bacteriolytic activity of Phage A1 on S. pyogenes ATCC 12202 infected at different MOIs over time. Each curve shows mean values \pm SD of one out of three experiments in triplicates; (D) One-step growth curves (OSGCs) of Phage A1 on S. pyogenes ATCC 12202. Mean values \pm SD from three independent experiments are shown. 
Table 2. Phage A1 characteristics.

\begin{tabular}{cc}
\hline Phage Parameter & Bacteriophage A1 (nm \pm SD *) \\
\hline Head & $60 \pm 2$ \\
Tail length & $187 \pm 4$ \\
Tail width & $10 \pm 1$ \\
Baseplate width & $16 \pm 2$ \\
Total length & $249 \pm 3$ \\
\hline
\end{tabular}

*Standard Deviation.

\subsection{Genome Sequence and Phylogeny of S. pyogenes Bacteriophage A1}

To obtain a more complete understanding of the molecular basis of the Phage A1 biology and its interaction with S. pyogenes, we first sequenced the genome of Phage A1. We determined that the Phage A1 genome is a circular dsDNA genome of 37,239 base pairs with a GC content of $37.9 \%$ (Figure $2 \mathrm{~A}$ ). In total, 52 putative gene products (Gps) were predicted, of which 23 encode hypothetical proteins that could not be identified by BlastP. The genomic organization of Phage A1 includes modules dedicated to gene regulation, DNA replication, DNA restriction, genome packaging, phage morphology and bacterial lysis, which is often observed for the Siphoviridae family members. The genome does not encode a hyaluronidase and no known virulence genes were identified. About half of the Phage A1 genome is dedicated to DNA packaging, phage structure and host cell lysis. The lysis module contains two predicted holin genes in addition to a peptidoglycan hydrolase lysin. The other half of the Phage A1 genome consists of regions dedicated to gene regulation and DNA replication; however, the majority of predicted Gps encode hypothetical proteins. Manual inspection of these hypothetical proteins resulted in some interesting observations. For instance, the Gp located downstream of the Gp for lysin (Gp51) showed 51\% identity to a prophage gene involved in external DNA acquisition inhibition called paratox. Furthermore, a large proportion of hypothetical proteins are conserved proteins with domains of unknown function (DUF) commonly detected in phages, which were previously shown to be a potential source of anti-host defense mechanisms [42]. Intriguingly, gp6 in the Phage A1 genome harbors almost 99\% identity to a putative DNAbinding antitoxin component found in S. pyogenes strain GA40634. Lastly, we identified a putative site-specific integrase (Gp52) and a lysogeny control module in the genome of Phage A1. The integrase gene is identical to the integrase of Phage Str01 but is unrelated to integrase genes found in S. pyogenes prophages. The most closely related integrase gene was predicted in Streptococcus bovimastitidis with an identity of almost 83\% (Table 3).

Since we identified a putative site-specific integrase along a lysogeny control module in the genome of Phage A1, we hypothesized that Phage A1 could be a temperate phage instead of a strictly lytic phage. To achieve a global overview of the relatedness of Phage A1 to both Phage A25 and Phage Str01, but also to phages of other streptococcal species and prophages present in S. pyogenes, we investigated the phylogenetic relatedness among streptococcal phages. We included sequenced lytic and temperate phages of S. pyogenes, S. pneumoniae, Streptococcus agalactiae, Streptococcus thermophilus, S. suis and Streptococcus dysgalactiae in addition to annotated prophages found in various M-type S. pyogenes strains. Initial alignments of the Phage A1 genome to lytic Phage A25 and temperate Phage Str01 already suggested that Phage A1 is highly similar to Phage A25 and Phage Str01. However, the phylogenetic analysis based on whole phage genomes revealed that Phage A1, Phage A25 and Phage Str01 form a separate branch in the generated phylogenetic tree (Figure 2B). S. pneumoniae Phage MM1 is the most closely related phage to these three phages with S. pyogenes prophages, $S$. suis and $S$. dysgalactiae phages being the most distantly related (Figure S1). However, temperate Phage Str01 is the most similar phage to Phage A1, further corroborating the possibility that Phage A1 is a temperate phage and not a strictly lytic phage. 
A

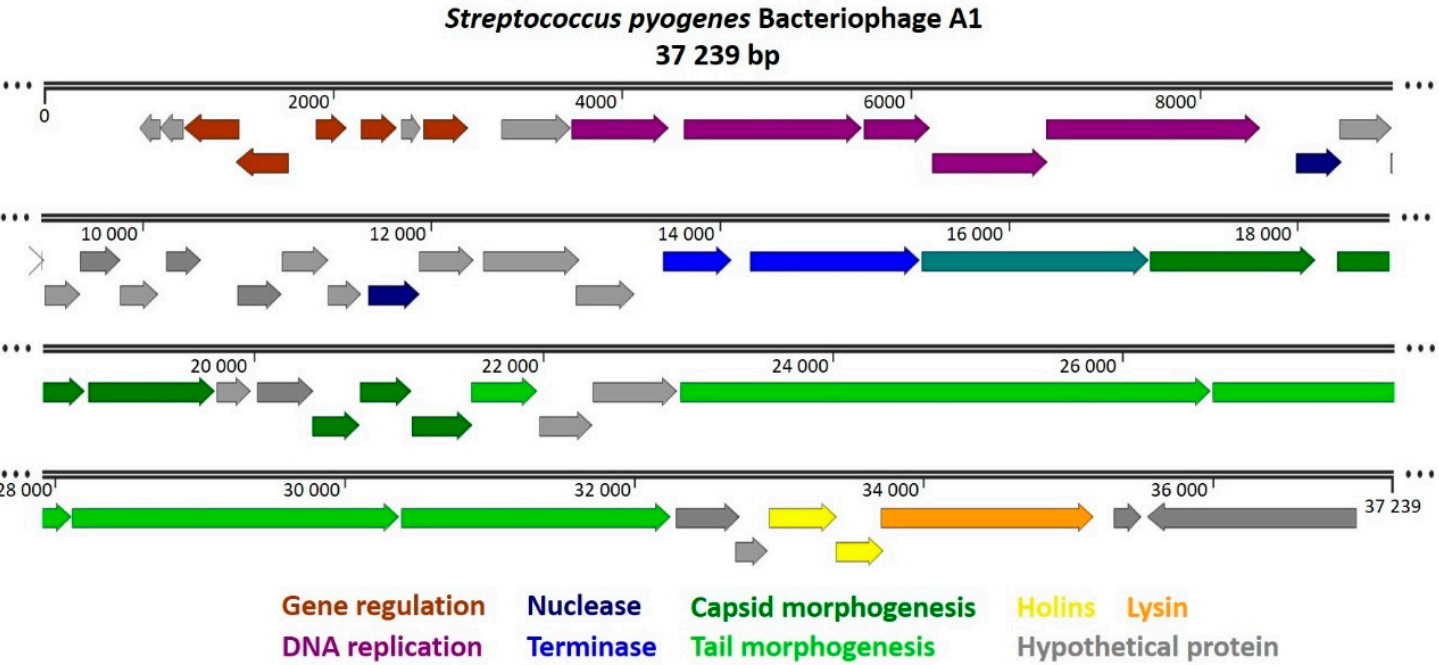

B

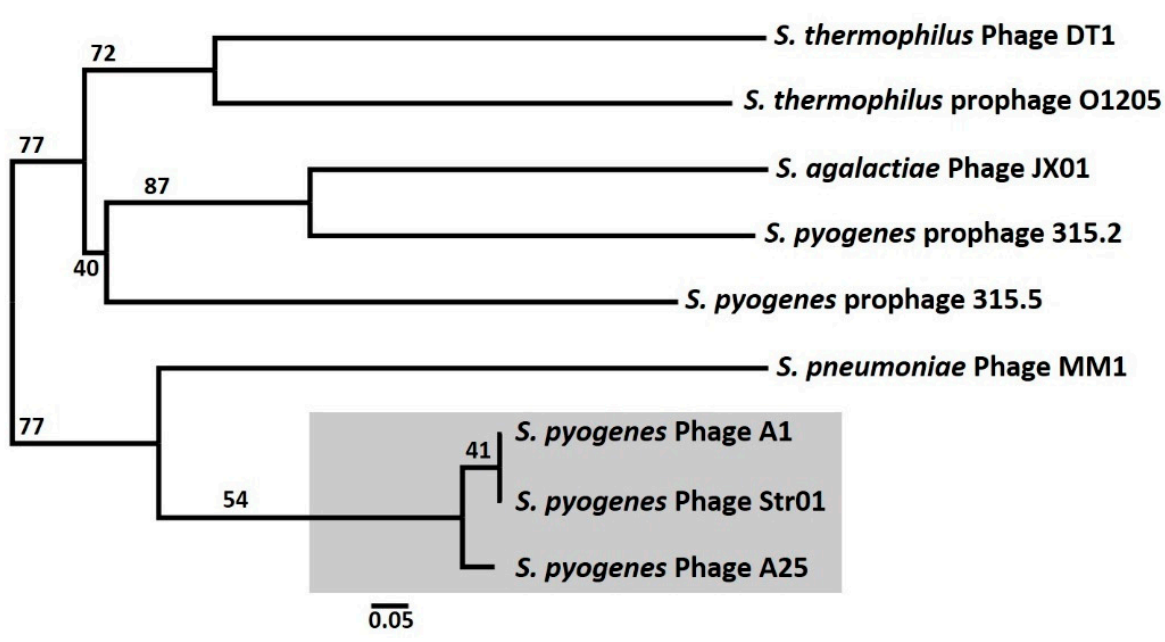

Figure 2. Genome sequence and phylogeny of S. pyogenes bacteriophage A1. (A) The Phage A1 genome is a 37,239 bp long circular dsDNA genome. Fifty-two gene products (Gps) were identiFigure 23. were encoding hypothetical proteins (gray). The genome follows the modular organization observed in other streptococcal phages, consisting of genes involved in regulation (brown), DNA replication (purple), nucleases (marine blue), DNA packaging (blue), portal protein (turquoise), capsid structure (dark green), tail morphogenesis (light green), holins (yellow) and a lysin (orange); (B) Whole genome-based phylogenetic tree of Phage A1 among streptococcal phages. The branch lengths are scaled in terms of the GBDP distance formula $\mathrm{D}_{0}$. Branch support was inferred from 100 pseudo-bootstrap replicates each. 
Table 3. Phage A1 genome annotation.

\begin{tabular}{|c|c|c|c|c|c|}
\hline Genomic Location (Gp Number) & Identified Protein (Species) & Direction & Accession Number & E Value & Identity $\%$ \\
\hline $667 . .801(\mathrm{Gp} 01)$ & $\begin{array}{l}\text { Hypothetical phage protein } \\
\text { (S. pyogenes Phage 10270.2) }\end{array}$ & $<=$ & ABF33863.1 & $1 e-21$ & 100 \\
\hline $808 . .960(\mathrm{Gp} 02)$ & Hypothetical protein (S. pyogenes) & $<=$ & WP_011054825.1 & $5 e-27$ & 100 \\
\hline 1332..1691 (Gp04) & $\begin{array}{l}\text { XRE family transcriptional regulator } \\
\text { (S. pyogenes Phage Str01) }\end{array}$ & $<=$ & APZ81910.1 & $2 e-79$ & 100 \\
\hline 1881..2099 (Gp05) & Cro family anti-repressor (S. pyogenes Phage 10270.2) & $\Rightarrow>$ & ABF33867.1 & $2 \mathrm{e}-44$ & 100 \\
\hline $2476 . .2610(\mathrm{Gp} 07)$ & Hypothetical protein (S. pyogenes Phage 10270.2) & $=>$ & ABF33611.1 & $5 e-24$ & 100 \\
\hline $2626 . .2940$ (Gp08) & $\begin{array}{l}\text { Helix-turn-helix transcriptional regulator } \\
\text { (S. pyogenes) }\end{array}$ & $=>$ & WP_011528544.1 & $2 e-69$ & 100 \\
\hline $3167 . .3649$ (Gp09) & Hypothetical Gp157 family protein (S. pyogenes) & $\Rightarrow>$ & WP_011528545.1 & $2 \mathrm{e}-108$ & 100 \\
\hline $3650 . .4330(\mathrm{Gp} 10)$ & AAA family ATPase (S. pyogenes MGAS1882) & $=>$ & AFC68359.1 & $2 \mathrm{e}-164$ & 99.56 \\
\hline $4432 . .5661(\mathrm{Gp} 11)$ & DEAD/DEAH box helicase (Streptococcus sp.) & $\Rightarrow$ & WP_011528546.1 & 0 & 100 \\
\hline $5677 . .6135$ (Gp12) & DUF669 domain-containing protein (Streptococcus sp.) & $=>$ & WP_002995969.1 & $2 \mathrm{e}-107$ & 100 \\
\hline $6147 . .6950(\mathrm{Gp} 13)$ & Bifunctional DNA primase/polymerase (S. pyogenes) & $=>$ & WP_011528547.1 & 0 & 99.25 \\
\hline $6940 . .8421$ (Gp14) & DNA primase (S. pyogenes) & $=>$ & WP_020905118.1 & 0 & 99.8 \\
\hline $8970 . .9326(\mathrm{Gp} 16)$ & Hypothetical protein (S. pyogenes) & $=>$ & WP_011018138.1 & $4 e-79$ & 100 \\
\hline $9323 . .9574(\mathrm{Gp} 17)$ & Hypothetical protein (S. pyogenes) & $=>$ & WP_011528549.1 & $4 e-54$ & 100 \\
\hline $9568 . .9852(\mathrm{Gp} 18)$ & $\begin{array}{l}\text { Hypothetical DUF3310-containing protein } \\
\text { (S. pyogenes) }\end{array}$ & $\Rightarrow>$ & WP_011017568.1 & $5 e-64$ & 100 \\
\hline 9849..10,118 (Gp19) & Hypothetical protein (S. dysgalactiae) & $\Rightarrow$ & SUN67275.1 & $1 e-58$ & 98.88 \\
\hline $10,170 . .10,409$ (Gp20) & Hypothetical TIGR01671 family protein (S. pyogenes GA40634) & $=>$ & ESA49192.1 & $6 e-33$ & 98.28 \\
\hline $10,660 . .10,971(\mathrm{Gp} 21)$ & $\begin{array}{l}\text { Hypothetical DUF1372-containing protein } \\
\text { (S. dysgalactiae) }\end{array}$ & $\Rightarrow$ & WP_081281150.1 & $9 e-62$ & 92.31 \\
\hline $10,971 . .11,294(\mathrm{Gp} 22)$ & Hypothetical protein (S. pyogenes Phage Str01) & $\Rightarrow$ & APZ81913.1 & $2 e-70$ & 100 \\
\hline $11,287 . .11,517(\mathrm{Gp} 23)$ & Hypothetical protein (S. pyogenes Phage A25) & $=>$ & YP_009191526.1 & $2 e-47$ & 100 \\
\hline $11,565 . .11,924(\mathrm{Gp} 24)$ & Endodeoxyribonuclease RusA (S. dysgalactiae) & $\Rightarrow>$ & WP_065359284.1 & $7 e-81$ & 97.48 \\
\hline $11,917 . .12,297$ (Gp25) & Hypothetical protein (S. pyogenes Phage Str01) & $=>$ & APZ81908.1 & $7 e-86$ & 100 \\
\hline $12,364 . .13,035(\mathrm{Gp} 26)$ & $\begin{array}{l}\text { Hypothetical DUF4417-containing protein } \\
\text { (S. dysgalactiae) }\end{array}$ & $=>$ & WP_155778398.1 & $3 e-164$ & 98.21 \\
\hline $13,005 . .13,415(\mathrm{Gp} 27)$ & Hypothetical protein (S. pyogenes Phage Str01) & $=>$ & APZ81907.1 & $2 e-87$ & 100 \\
\hline $13,608 . .14,087$ (Gp28) & Terminase (small subunit) (S. dysgalactiae) & $=>$ & WP_003058573.1 & $6 e-111$ & 100 \\
\hline
\end{tabular}


Table 3. Cont.

14,209..15,387 (Gp29)

15,399..16,976 (Gp30)

16,979..18,127 (Gp31)

$18,274 . .18,837(\mathrm{Gp} 32)$

18,856..19,734 (Gp33)

19,745..19,981 (Gp34)

20,025..20,417 (Gp35)

20,407..20,733 (Gp36)

20,733..21,092 (Gp37)

21,092..21,511 (Gp38)

21,504..21,962 (Gp39)

21,977..22,345 (Gp40)

22,345..22,929 (Gp41)

$22,946 . .26,617(\mathrm{Gp} 42)$

$26,626 . .28,116$ (Gp43)

28,120..30,381 (Gp44)

30,393..32,258 (Gp45)

32,291..32,737 (Gp46)

32,703..32,930 (Gp47)

32,938..33,405 (Gp48)

33,398..33,733 (Gp49)

33,708..35,180 (Gp50)

35,318..35,509 (Gp51)

$35,552 . .36,991(\mathrm{Gp} 52)$
Terminase (large subunit) (S. dysgalactiae)

Portal protein (S. dysgalactiae)

Minor capsid protein (S. dysgalactiae)

Scaffolding protein (S. pyogenes Phage A25)

Major capsid protein (Streptococcus canis)

Hypothetical protein (S. dysgalactiae)

Hypothetical protein (S. dysgalactiae)

Minor capsid protein (S. pyogenes Phage Str01)

Capsid protein (S. pyogenes Phage A25)

Capsid protein (S. dysgalactiae)

Major tail shaft protein (S. pyogenes Phage A25)

Hypothetical protein (S. dysgalactiae)

Hypothetical Gp15 protein (Streptococcus equi subsp. zooepidemicus)

Tail tape measure protein (S. pyogenes Phage Str01)

Tail endopeptidase (S. pyogenes Phage Str01)

Minor structural tail protein (S. pyogenes Phage A25)

Structural tail protein (S. pyogenes Phage A25)

Hypothetical DUF1366-containing protein (S. dysgalactiae)

Hypothetical protein (S. pyogenes Phage Str01)

Class I Holin (S. pyogenes Phage A25)

Class III Holin (S. dysgalactiae)

Lysin (S. pyogenes Phage A25)

Hypothetical Paratox protein (S. pyogenes)

Hypothetical Recombinase family protein (S. bovimastitidis)

\section{$=>$}

$=>$

$=>$
$=>$

$\Rightarrow$

$=>$
$=>$

$\Rightarrow$

$=>$

$\Rightarrow$

$\Rightarrow$

$\Rightarrow$

$=>$

$=>$

$=>$
$=>$

$=>$

$<=$
WP_003058577.1

WP_003058556.1

WP_003058578.1

YP 009191535.1

WP_164406187.1

WP_003058596.1

WP_003058548.1

APZ81883.1

YP_009191540.1

WP_155783005.1

YP_009191542.1

WP_155783003.1

KIS17966.1

APZ81886.1

APZ81874.1

ALF02720.1

ALF02721.1

WP_003058584.1

APZ81920.1

YP_009191551.1

WP 003058565.1

YP_009191553.1

WP_136110174.1

WP_071794279.1
0

0

$2 \mathrm{e}-12$
0

$3 e-46$

$9 \mathrm{e}-91$

$8 \mathrm{e}-70$

$4 \mathrm{e}-82$

$4 \mathrm{e}-96$

$6 e-107$

$1 \mathrm{e}-81$

$4 \mathrm{e}-88$

0

0

$5 e-97$

$4 \mathrm{e}-45$

$2 \mathrm{e}-106$

$6 e-74$

0

$2 e-06$

0

100

100

100

100

100

100

100

100

100

100

100

$68.39 \%$

100

100

100

100

99.3

100

98.71

100

100

51.22

82.88 


\subsection{Phage A1 Is Potentially Temperate and Phage A1 Survivors Acquire Phage Resistance}

To test whether Phage A1 could be a temperate phage, we assessed its ability to integrate into the genome of S. pyogenes strains ATCC 12202 and SF370. Cultures in midlogarithmic growth phase were infected with Phage A1, after which we spun down cleared lysates and plated pellets on blood agar plates to check for viable clones. To omit the possibility of picking up contaminating phage DNA, single colonies were selected and passaged twice before testing for the presence of Phage A1 products by PCR. The genomic DNA of phage-surviving colonies was subjected to PCR to screen for phage integration with primers specific to Phage A1 and primers that should not yield a product when the Phage DNA is integrated into the host genome (Figure 3A top). We could amplify a product from the genomic DNA of 6 of 14 SF370 and 13 of 15 ATCC 12202-surviving colonies when we screened for the Phage A1 integrase gene (Figure 3A bottom). In contrast, no amplicons could be detected when the PCR covered the circularization junction of the Phage A1 genome (Figure 3A), confirming that the Phage A1 genome is present in the isolated $S$. pyogenes genomic DNA.

A

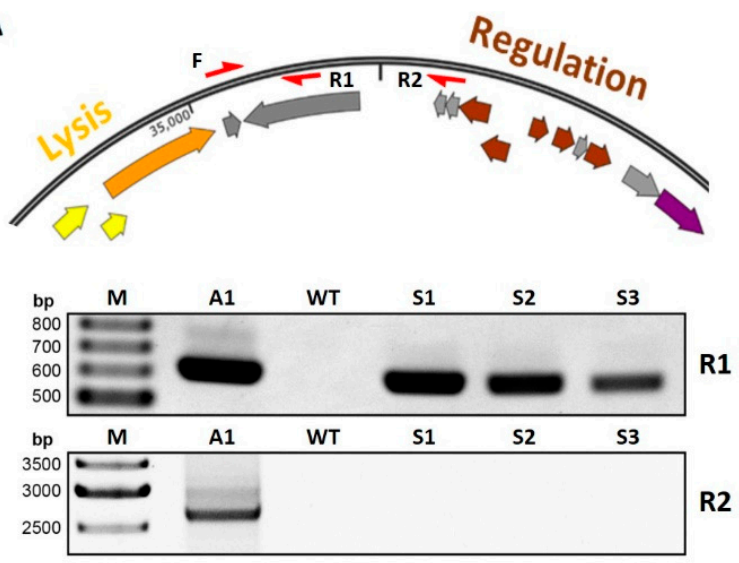

B

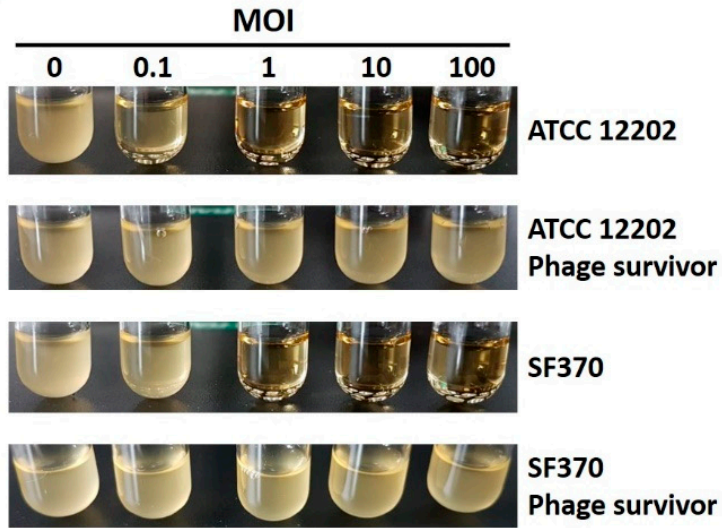

Figure 3. Phage A1 is likely a temperate phage, and Phage A1 survivors become resistant to subsequent infections. (A, top) Genomic DNA was screened by PCR for phage integration with primers specific to Phage A1 (F + R1) and primers that should not amplify an amplicon if the Phage DNA is integrated into the genome of S. pyogenes (F + R2) (F: forward, R: reverse); (A, bottom) Agarose gel showing PCR amplicons of both combinations F + R1 (up) and F + R2 (down) in S. pyogenes ATCC 12202. A1: Phage A1 genome, WT: wild type S. pyogenes ATCC 12202, S1: phage survivor 1, Scheme 2. phage survivor 2 and S3: phage survivor 3; (B) Representative pictures of S. pyogenes ATCC 12202 and SF370, and their phage-surviving strains after $4 \mathrm{~h}$ of infection at MOIs 0.1, 1, 10 and 100 compared to uninfected growth (MOI 0). Each image represents WT strains and one out of three phage-surviving clones that were infected in biological triplicates.

Having established that Phage A1 DNA is present in S. pyogenes after infection, we investigated whether phage-surviving S. pyogenes clones become resistant to Phage A1 infection. We infected three Phage A1-surviving clones and their WT S. pyogenes strains with Phage A1 at MOIs ranging from 0.1 to 100. Phage A1-surviving clones of both ATCC 12202 and SF370 were able to grow even when infected at an MOI of 100. In contrast, WT strains were rapidly cleared when infected at MOI 0.1 for ATCC 12202 or MOI 1 for SF370 (Figure 3B).

\subsection{Phage A1-Surviving Strains Do Not Alter the Host Immune Response or Tolerance to Antibiotics}

Phage lysogeny has the potential to alter phenotypes of their hosts. Therefore, we investigated whether Phage A1 survivors behave differently than their WT counterparts. First, we determined growth characteristics to investigate the fitness of survivor strains. We observed a prolonged lag phase for all three tested ATCC 12202 phage-surviving clones, and these strains did not reach equal ODs when entering stationary growth phase. In contrast, each isolated phage-surviving SF370 strain behaved differently when compared to each 
other or to WT SF370. Surviving clone 1 grew equally during lag phase and early log phase but entered stationary phase earlier. Surviving clone 2 grew equal to WT but reached a higher OD. Surviving clone 3 showed a prolonged lag phase, similar to phage survivor ATCC 12202 strains (Figure S2).

Since the antibiotic treatment failure of severe S. pyogenes-associated disease has been reported and phage therapy could provide an alternative, we examined whether the pathogenicity of Phage A1 survivors was affected in comparison to WT S. pyogenes. In the body, after S. pyogenes invades soft tissue and establishes systemic infection, it encounters various types of immune cells. Here, monocytes fulfil crucial functions during bacterial infection such as phagocytosis, antigen presentation and cytokine production [43]. We used BLaER1 cells to represent the encountered monocytes during systemic infection. BLaER1 are immortalized, genetically modified B-cells from a leukemia patient that stably express an inducible $\mathrm{C} / \mathrm{EBP} \alpha$ transgene. Induction of the transcription factor $\mathrm{C} / \mathrm{EBP} \alpha$ leads to the irreversible differentiation of BLaER1 cells into monocyte-like cells which recapitulate monocytic functions [41]. First, we investigated cytokine production by BLaER1 cells after infection with WT S. pyogenes SF370 and phage-surviving strains. We observed that infection with both WT and Phage A1 survivors results in a clear proinflammatory response, but found no difference in the amount of IL- 6 or IL-1 $\beta$ produced by cells infected with WT SF370 compared to Phage A1 lysogen-infected cells (Figure 4A). Continuing to test the pathogenicity of Phage A1 survivors, we measured LDH release to determine the cytotoxic ability upon infection. In agreement with the cytokine profiles, we did not detect significant differences in released LDH in culture medium after infecting BLaER1 cells with WT SF370 or Phage A1-surviving strains (Figure 4B).

As the tolerability of $S$. pyogenes towards antibiotics can be influenced upon phage lysogenization or chromosomal insertion of prophage-associated genetic elements [44], we investigated the antimicrobial resistance profile against the commonly used antibiotic ampicillin. Here, we observed that Phage A1-surviving strains are not enhanced in their ability to grow in the presence of ampicillin, showing no increase in MIC (Figure 4C).

\subsection{CRISPR-Cas-Mediated Spacer Acquisition Is Increased in the Absence of a Capsule}

It is well known that $S$. pyogenes produces an HA capsule, which has been shown to play an important factor in the defense against phage infection or in immune evasion [16-18]. However, capsule production differs greatly among strains and under different growth conditions [45]. To examine the importance of the capsule in the defense against Phage A1 infection, we investigated the lysis profile of Phage A1 on commonly studied S. pyogenes SF370 and clinical isolate S. pyogenes ISS3348. The latter strain contains a naturally occurring mutation in $\operatorname{cov} R S$ resulting in enhanced capsule production. Additionally, has $A \mathrm{KO}$ mutants of SF370 and ISS3348 were tested to identify the role of the capsule during Phage A1 infection. S. pyogenes SF370 showed rapid lysis after Phage A1 infection at MOI 1 and MOI 0.5, but was delayed at MOI 0.1. A minor decrease in OD was observed after overnight infection at MOI 0.05 and no lysis was observed at lower MOIs than 0.05 . The lytic phenotype on SF370 $\Delta$ has A was increased compared to WT SF370, with accelerated lysis occurring up to MOI 0.05. Lysis at MOI 0.01 could not be detected. In contrast, ISS3348 showed a completely resistant phenotype to Phage A1 infection with no lysis occurring at the tested MOIs. However, the lysis profile of Phage A1 on ISS3348 $\Delta$ has $A$ was similar to that of SF370, showing that ISS3348 becomes susceptible to Phage A1 infection in the absence of its capsule (Figure 5A). 
A

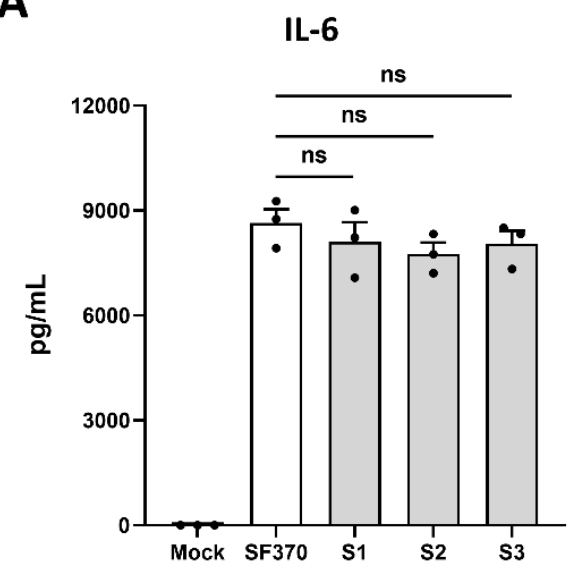

B

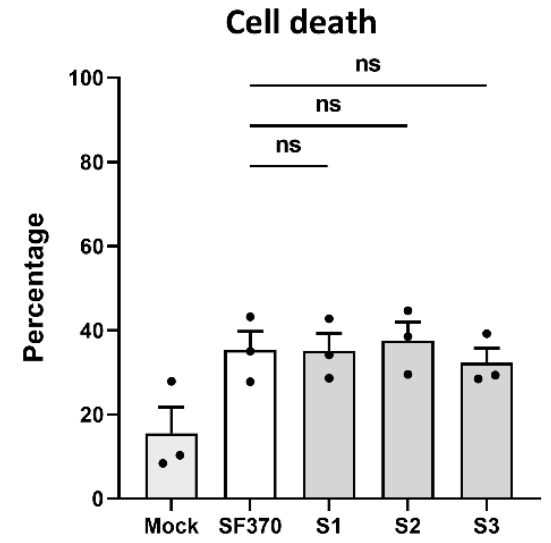

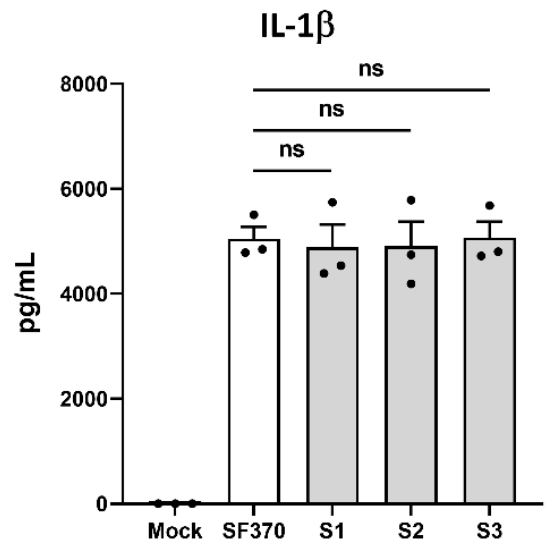

C

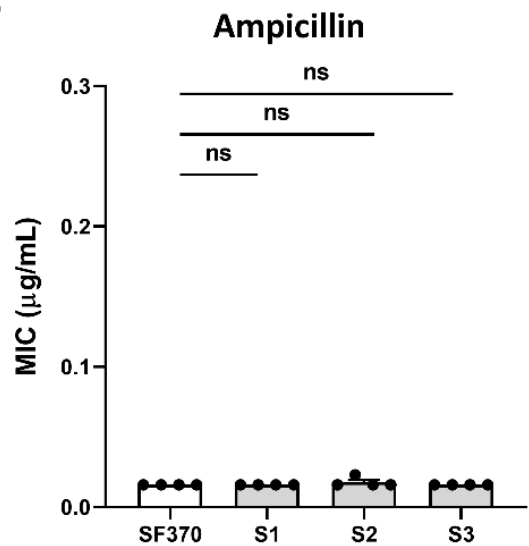

Figure 4. Phage A1-surviving strains do not influence host immune responses or antibiotic tolerance compared to wild type. (A) Overnight cytokine production by BLaER1 cells after infection with WT $S$. pyogenes SF370 and phage-surviving strains. (B) The percentage of BLaER1 cell death after infection with Phage A1 survivors or WT S. pyogenes SF370 is shown. (A,B) Mock: buffer control, S1: phage survivor 1, S2: phage survivor 2 and S3: phage survivor 3; (C) Ampicillin susceptibility profiles of S. pyogenes SF370 and survivor strains are shown. S1: phage survivor 1, S2: phage survivor 2 and S3: phage survivor 3; (A-C) Pooled data from three or four independent experiments are shown. Statistical significance between groups was determined by one-way ANOVA tests.

Since CovRS regulates the expression of up to $15 \%$ of the S. pyogenes genome-including the has $A B C$ operon-[46] it is not known whether an altered infection of ISS3348 would be a direct consequence of the mutated $\operatorname{cov} R S$ resulting in the thickened capsule or other background-related factors compared to SF370. Therefore, we included S. pyogenes 5448 and 5448AP, which are identical except for an inactivated CovRS system in 5448AP [34]. We assessed plaquing efficiency to confirm the ability of Phage A1 to infect the aforementioned M1 serotype S. pyogenes strains and their mutants. Here, we confirmed that Phage A1 infectivity was slightly increased on SF370 $\Delta$ has A compared to SF370. Additionally, Phage A1 was unable to form PFUs on strain ISS3348 but we could detect PFUs on ISS3348 has $A$, which were up to one order of magnitude less compared to WT SF370. The infection of strain 5448 was 2.5 to 3 orders of magnitude lower compared to SF370, but PFU counts showed a similar infection efficiency as on 5448AP (Figure 5B). To further verify that the increased susceptibility of the has $A \mathrm{KO}$ mutants is due to the absence of the capsule, we included hyaluronidase in the growth medium of WT S. pyogenes strains to prevent capsule formation and repeated EOP assays. Here, we confirmed that the infection efficiency of Phage A1 was increased by around one order of magnitude when S. pyogenes was grown in hyaluronidase-containing media, similar to the difference between WT SF370 and SF370 $\Delta$ has $A$ without hyaluronidase in growth media (Figure S3A). Strikingly, WT ISS3348 
shifted from a completely resistant phenotype to a susceptible phenotype when grown in hyaluronidase-containing media. The infection of WT ISS3348 by Phage A1 was similar to the infection of ISS3348 4 has $A$. The addition of hyaluronidase in the growth media had no additional effect on the infection of ISS3348 $\Delta$ has $A$, confirming that the S. pyogenes capsule is pivotal in the defense against phage infection (Figure $5 \mathrm{C}$ ).

A SF370

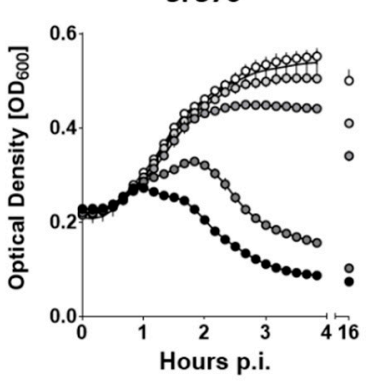

SF370 DhasA

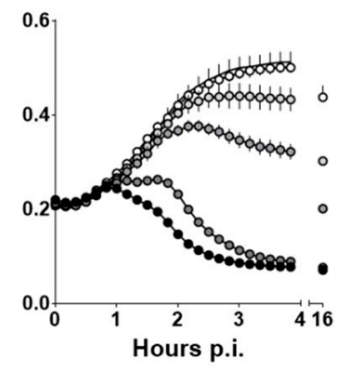

ISS3348

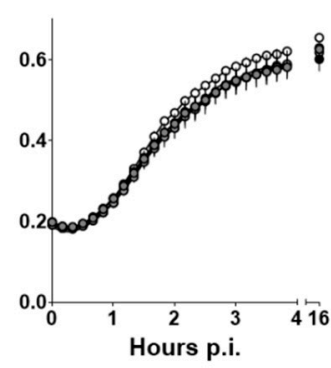

ISS33484hasA

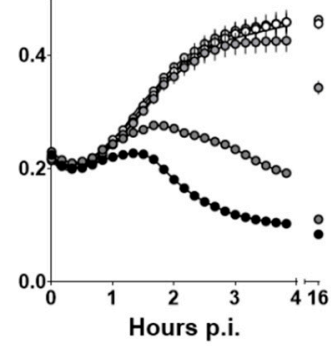

- MOI 1 MOI $0.5 \circ \mathrm{MOI} 0.1 \mathrm{O}$ MOI 0.05 O MOI 0.01 - Uninfected

B

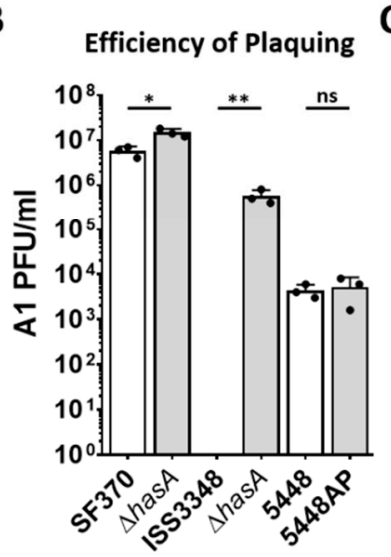

$\mathrm{C}$

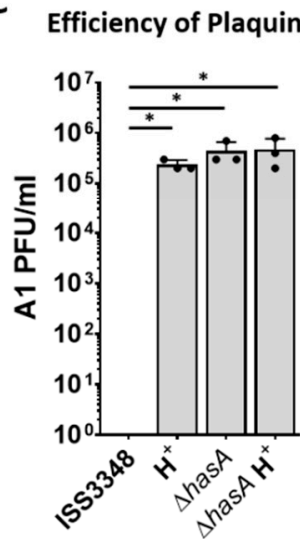

D

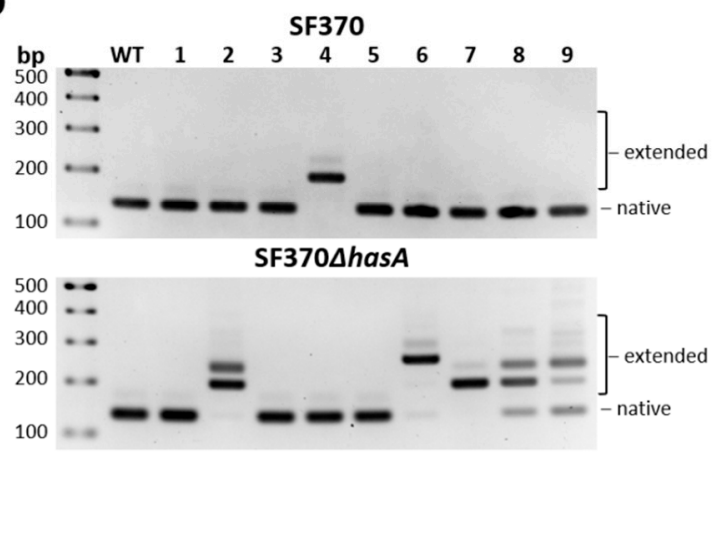

Figure 5. Impaired capsule-based phage resistance results in more detectable CRISPR-Cas-mediated spacer acquisition. (A) Lysis profiles of Phage A1 on S. pyogenes SF370, ISS3348, and their isogenic $\Delta$ has A strains. Each curve shows mean values $\pm \mathrm{SD}$ of one out of three experiments in triplicates; (B) Phage A1 efficiency of plaquing (EOP) on various M1 serotype $S$. pyogenes, and their isogenic $\Delta$ has A or CovS mutant strain; (C) Phage A1 EOP on S. pyogenes ISS3348 and ISS3348 $\Delta$ has A grown in the absence or presence of hyaluronidase $\left(\mathrm{H}^{+}\right) ;(\mathbf{B}, \mathbf{C})$ Results are presented as mean values \pm SD from three independent experiments. $p<0.05$ determined by paired $\mathrm{t}$ tests was considered statistically significant. ${ }^{*} p<0.05,{ }^{* *} p<0.01, \mathrm{NS}=\mathrm{not}$ significant; (D) Representative agarose gels showing amplified CRISPR arrays of WT S. pyogenes SF370 (up), SF370 $\Delta$ has $A$ (down), and 9 surviving colonies (1-9) for both strains after Phage A1 infection.

Although Phage A1 infectivity was increased for the has $A$ KO mutants, we observed that phage-surviving colonies in the absence of a capsule could still be recovered after overnight growth. Consequently, we investigated intracellular mechanisms by which $S$. pyogenes could resist phage infection. We established a spacer acquisition assay adapted from a previous study [47] to test whether the type II-A CRISPR-Cas system of S. pyogenes could acquire new spacers deriving from Phage A1. S. pyogenes SF370 and SF370 4 has A were infected at MOI 1 after which the cleared culture was probed for viable colonies on blood plates. Surviving colonies were screened for spacer acquisition by PCR after excluding the presence of Phage A1 DNA in the same strain. We detected the acquisition of a new spacer in 2 out of 27 tested surviving single colonies of WT SF370. Interestingly, we observed spacer acquisition in 12 out of the 27 tested single colonies in the has $A \mathrm{KO}$ strain. Additionally, multiple acquired spacers could be amplified from the genome of SF370 4 has $A$, suggesting that spacer acquisition is increased in the absence of a capsule (Figure 5D). Sequencing of acquisition events confirmed that the spacers derive from the Phage A1 genome. The acquired spacers in WT SF370 targeted structural proteins encoding 
the major capsid protein (Gp33) and the minor structural tail protein (Gp44) in the genome of Phage A1. In addition to Gps 33 and 44, the putative transcriptional regulator (Gp08), DNA primase (Gp14), structural tail protein (Gp45) and the lysin (Gp50) were targeted in SF370 $\Delta$ has A (Figure S3B).

\subsection{Membrane Vesicles of S. pyogenes Bind Phages and Limit Phage Infection}

Assessing the lysogeny and CRISPR spacer acquisition of S. pyogenes SF370 showed that the type II CRISPR-Cas system integrated new spacers into its CRISPR array and that the strain was less efficiently lysogenized by Phage A1. In contrast, nearly all phagesurviving S. pyogenes ATCC 12202 colonies contained detectable Phage A1 DNA. Furthermore, the capsule of ISS3348 seems to be the critical determinant in the defense against phage infection. Therefore, we hypothesized that mechanisms by which S. pyogenes survives phage infection can vary among strains and are not restricted to lysogeny, the capsule or CRISPR-Cas immunity. Another strategy by which bacteria can limit phage infection is by the increased production of MVs, which could potentially serve as a decoy for phages [48]. To explore the potential role of S. pyogenes-derived MVs in the defense against Phage A1 infection, we followed phage infection over time with SEM imaging after infecting S. pyogenes SF370 with Phage A1 at an MOI of 10. Here, we observed that phages are bound to their host after 5 min of incubation, and disturbed bacterial membranes and potential MV formation became visible after $25 \mathrm{~min}$ of infection. MV production was clearly observed after 45 min of infection. The first lysed cells appeared between 45 and 60 min of infection. Additionally, most S. pyogenes cells were lysed after 90 min (Figure 6A).
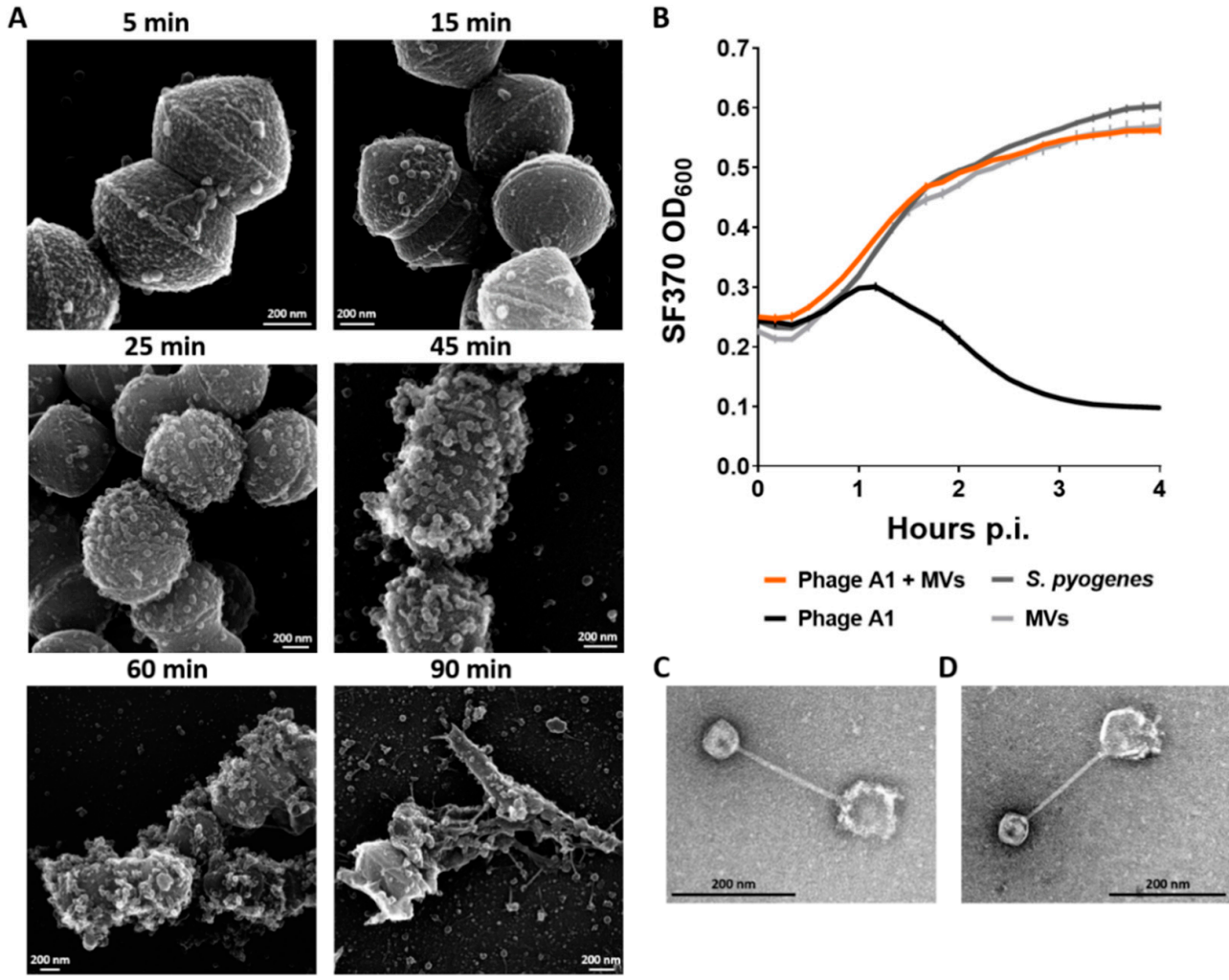

Figure 6. S. pyogenes-derived membrane vesicles inhibit phage infection. (A) Representative SEM micrographs of S. pyogenes SF370-infected with Phage A1 at MOI 10 are shown after 5, 15, 25, 45, 60 and 90 min of coincubation; (B) Growth curves of WT SF370 after Phage A1 infection that was either pre-incubated with membrane vesicles (MVs) or left untreated. Phage:S. pyogenes:MV ratio of 1:1:1000 is shown. Mean values \pm SD from one out of three independent experiments in Table 1 . bound to a S. pyogenes SF370-derived MV; (D) TEM micrograph of a S. pyogenes ISS3348-derived MV bound to Phage A1; (C,D) Representative images are shown for at least three sample preparations. 
To evaluate whether increased amounts of MVs produced by S. pyogenes are able to limit phage predation, we incubated purified MVs of S. pyogenes SF370 with Phage A1 before infecting S. pyogenes SF370. Indeed, we observed the inhibition of phage infection with phage:S. pyogenes:MV ratios of 1:1:1000 (Figure 6B). In contrast, we did not observe the inhibition of phage infection when we infected S. pyogenes at higher phage to MV ratios in favor of phage amounts (not shown), suggesting a concentration-dependent inhibitory effect. To examine whether the observed neutralizing effect is due to the direct binding of the phage to MVs, we visualized coincubated Phage A1 and purified S. pyogenes SF370-derived MVs with TEM. Here, we observed that phages were bound to MVs after 15 min with clear individual contact between the phage tail and the MVs (Figure 6C). To investigate whether the binding of Phage A1 to MVs is a general phenomenon among $S$. pyogenes strains, we purified MVs from clinical isolate ISS3348 and tested the interaction between Phage A1 and ISS3348-derived MVs. We observed that phages were bound to MVs of ISS3348 after coincubation, and interaction between phage and MVs was observed (Figure 6D).

\section{Discussion}

In this study, we describe a previously uncharacterized S. pyogenes phage in detail. We show that Phage A1 is a putative temperate phage and that its DNA can be detected in S. pyogenes genomes, resulting in strains that are resistant to subsequent infections. Importantly, these Phage A1-survivor strains do not develop ampicillin tolerance or become more virulent than their WT counterpart.

To date, the best-studied phage of S. pyogenes-that is not a prophage-is Phage A25. Electron micrographs showed that Phage A25 belongs to the Siphoviridae [26], and although minor differences exist in some phage dimensions, the morphology of Phage A1 is highly similar to that of Phage A25. The estimated burst size of Phage A25 was determined at 12 to $32 \mathrm{PFU}$ per bacterial cell depending on the host strain that was investigated $[27,28]$. Similarly, we observed an average burst of 31 PFUs per infected cell for Phage A1 when propagated on S. pyogenes ATCC 12202. However, this number could differ when tested on different $S$. pyogenes strains since the lysis profile also showed minor differences in the infection cycle between S. pyogenes strains ATCC 12202 and SF370.

Streptococcal phages typically feature a modular genome organization with a clear distinction between regions dedicated to phage structure and host cell modulation [49]. Recently, two S. pyogenes phage genomes were sequenced where this modular genetic arrangement was observed as well $[30,50]$. The Phage A1 genome was highly similar to temperate Phage Str01 and virulent Phage A25, with Phage Str01 being its closest relative. Compared to Phage Str01, Phage A1 accommodates 37 more nucleotides in a non-coding region dedicated to gene regulation and 132 nucleotides more in a hypothetical protein produced by $g 23$ that were present in the Phage A25 genome. Furthermore, we identified two single nucleotide differences, one of which was a synonymous substitution in the DNA primase. The other difference, however, was a non-synonymous mutation in the DUF1366-protein changing a valine to isoleucine in comparison to Str01. Besides the missing integrase gene and surrounding genetic regions in Phage A25, multiple (non-) synonymous mutations were present in several structural proteins but also in hypothetical proteins. Two amino acid changes were detected in the C-terminus of the class I Holin, which were not present in the Phage Str01 genome. One of the Phage A1 genes ( $g 52)$ shared identity with a recombinase family protein found in S. bovimastitidis and is identical to the site-specific integrase gene of Phage Str01, which is noteworthy since Phage A1 is historically implicated to be a strictly lytic phage $[18,24]$. Here, we observe that the integrase gene locates in the vicinity of the gene regulation module, which is expressed early during infection (data not shown). Early expressed genes may be involved in lysogenic-lytic lifecycle decisions, and local transcript levels could therefore determine which replication cycle the phage enters, e.g., high concentrations of integrase transcripts promoted a lysogenic state of mycobacteriophages upon infection [51]. Phage A25 escaped from lysogeny by the 
deletion of its integrase [30], and, based on the genomic similarity and differences between Phage Str01, Phage A25 and Phage A1, it is tempting to speculate that Phage A1 served as an intermediate phage in the conversion of Phage A25 from a temperate to a strictly lytic phage.

PCR analysis showed that Phage A1 DNA can be amplified from the genome of nearly all S. pyogenes ATCC 12202- and some SF370-surviving colonies, indicating that Phage A1 could be a temperate phage. Furthermore, surviving Phage A1 infection in both parental S. pyogenes strains resulted in complete resistance against subsequent phage infections, most likely by providing superinfection immunity. Previous hints towards superinfection immunity against Phage A25 were found by McCullor and colleagues, where they observed that $S$. pyogenes strains containing high homology prophages to Phage A25 were resistant to infection [30]. The mechanism of resistance was experimentally confirmed by complementing the $c I$-like repressor and regulation module of an S. pyogenes prophage-representing the deleted lysogeny module that is absent in Phage A25 but present in Phage A1-in multiple strains that were susceptible to Phage A25 infection. As a result, complemented strains converted into phage-resistant strains through the expression of the $c I$-like repressor, which prevents the transcription of invading homologous phages and terminates phage replication [30].

S. pyogenes is one of the most clinically relevant human pathogens causing over 500,000 deaths each year [6]. Prophages in the genome of S. pyogenes have been shown to be a major contributor to virulence of this pathogen by transmitting virulence factors that altered its pathogenic behavior [52-54]. We did not identify known virulence genes in the genome of Phage A1, but previous studies have shown that lysogeny can significantly influence the host cell by altering the bacterial surface or transduce virulence factors to other host cells [55]. Our lab and others previously described the temperate phagemediated transfer of the streptococcal superantigen genes ssa [56] and speA [57] among clinical S. pyogenes isolates. Nevertheless, phage therapy holds great potential to treat complicated infections where antibiotics are ineffective. Because temperate phages have the ability to integrate into host genomes and mediate the transfer of potential virulence genes between bacteria, strictly lytic phages are preferred subjects for therapeutic purposes [58]. In this study, however, we did not observe an increased antibacterial resistance phenotype or pathogenicity of Phage A1 survivors compared to WT bacteria, which holds promise for the development of Phage A1 or Phage A1-derived products for therapeutic uses. For instance, Phage A1 could be engineered towards a lytic phage by the removal of the putative integrase, or to disturb intracellular processes that are important for bacterial survival after lysogenization [59]. However, Phage A1 survivors displayed a superinfection immunity phenotype and were insensitive to subsequent phage infections. Additionally, early studies have described increased virulence of phage-surviving S. pyogenes, showing that phage survivors were enhanced in their ability to kill mice [24], although a real estimation of virulence is difficult due to discrepancies between our infection model and mouse models used in the 1950s. In conclusion, a cautious approach towards temperate phages in phage therapy should be kept in mind and we suggest the development of phage endolysins from streptococcal phages for their antibacterial potential over the therapeutic use of Phage A1 itself, to support the treatment of severe streptococcal disease where antibiotics failed to resolve the infection [60].

The hyaluronic acid capsule is a major virulence determinant for S. pyogenes and highly encapsulated S. pyogenes strains are associated with more severe disease and increased resistance to neutrophil-mediated killing [16,17]. Moreover, the removal of the HA capsule increased the phage sensitivity of S. pyogenes [18,30]. Here, we were able to confirm the critical role of the capsule in phage defense. We observed that Phage A1 infects SF370 as efficiently as its replication strain ATCC 12202 but did not propagate in S. pyogenes ISS3348. S. pyogenes ISS3348 is a clinical isolate with a mutation in the two-component regulatory system CovRS. Mutations in CovRS have been shown to result in highly encapsulated S. pyogenes strains and could explain the observation that ISS3348 is resistant to phage 
infection since increased capsule production blocks phage adsorption [14]. In agreement, Phage A1 infection of ISS3348 was observed when has A was deleted from the genome or when the capsule was removed by enzyme treatment in the growth media, confirming that the capsule is a direct cause of impenetrability. However, we observed equal infection efficiencies of Phage A1 on S. pyogenes strains 5448 and 5448AP, indicating that backgroundrelated factors in addition to the thickness of the capsule are involved in phage resistance and can differ between strains.

Interestingly, we observed that the type II-A CRISPR-Cas system of SF370 $\Delta$ has A showed elevated spacer acquisition events compared to WT spacer acquisition levels. Previous studies showed that CRISPR loci were among the most highly transcribed regions in bacterial cells during normal growth [61,62], suggesting that the high-level expression of CRISPR-Cas systems does not result in fitness defects and is advantageous for survival, at least in some environments. In agreement, no differential expression of the type II-C CRISPR-Cas genes in C. jejuni was observed upon phage infection [63]. Therefore, we hypothesized that native expression levels of the SF370 CRISPR-Cas system are sufficient for phage defense but the increased entry of Phage A1 into cells without a capsule and the involved dynamics hereof resulted in increased phage recognition by the CRISPR-Cas system. Until now, the CRISPR-Cas system of $S$. pyogenes has not been investigated in its native host due to the previous lack of infectious elements to challenge $S$. pyogenes. Although the type II-A CRISPR-Cas system has been studied extensively in a heterologous host [47,64], it would be most important to study the type II-A CRISPR-Cas system in its native settings. For instance, host-specific factors are absent in previous experimental setups and could play important parts in CRISPR immunity, as shown for other organisms [65]. Based on our results, Phage A1 and S. pyogenes SF370 LhasA provide an ideal system to study the CRISPR-Cas system to gain a deeper understanding of CRISPR-Cas biology in its original host, which ultimately could lead to the optimization of CRISPR-Cas9-based tools for biotechnological purposes.

Another characteristic of $S$. pyogenes strains that acquired $\operatorname{cov} R S$ mutations is the hyper production of MVs [35]. MVs are naturally secreted by cells of all kingdoms of life and exhibit a large diversity of biological roles [66]. Because the surface of MVs is highly similar to that of their host cells, MVs can serve as a decoy for phages and limit phage infection [66,67]. In this study, we observed highly disturbed bacterial membranes and MV formation during the course of infection. Additionally, incubating purified MVs of S. pyogenes SF370 with Phage A1 before the infection of S. pyogenes SF370 inhibited phage infection. We could further show that the observed neutralizing effect is due to direct binding of the phage to MVs that could also be applied to other strains of S. pyogenes. Other studies have reported similar observations. Escherichia coli outer membrane vesicles (OMVs) were shown to neutralize bacteriophage $\mathrm{T} 4$ by the formation of complexes between phage and OMVs [48]. Moreover, the OMVs of Vibrio cholerae reduced phage infection in a dose- and receptor-dependent manner [67], providing evidence that MVs act as a first line of defense against phage predation that can be applied to a large variety of bacterial species. However, the extent to which MVs contribute towards the phage resistance of S. pyogenes in natural habitats is less understood since the concentrations of MVs that naturally accumulate during infection are unknown. Additionally, mutants of S. pyogenes that are unable to produce MVs have not been obtained to date, which makes it impossible to quantify the role that MVs play during infection. Nevertheless, it is reasonable to assume that MVs can be protective of phage infection when a desirable ratio of MVs and phages has accumulated in its micro-environment.

In summary, we propose a multistage interaction model between S. pyogenes and Phage A1.

MVs produced by S. pyogenes are able to scavenge phage particles from the environment and reduce the infection pressure. When phages reach the cell surface of $S$. pyogenes, they have to overcome a hyaluronic acid capsule to bind to their receptor. When a phage manages to bind its receptor and injects its DNA into S. pyogenes, new phages are produced 
in the majority of infected cells, which are released during cell burst. When the capsule is absent or reduced in thickness, phage infectivity is increased and intracellular anti-phage defense systems-such as CRISPR-Cas-become more prominent. In a minor fraction of infected cells, the Phage A1 genome becomes present in the S. pyogenes genome enabling the survival of the bacterial host. However, Phage A1-surviving clones do not become more virulent than their WT counterpart in vitro or develop resistance towards ampicillin. In conclusion, this work provides novel insight into survival strategies utilized by S. pyogenes to combat phage predation and describes a means to study the type II-A CRISPR-Cas system in its native host. Lastly, we propose that Phage A1 gene products-such as the endolysin — have the potential to be harnessed for the development of anti-bacterial agents.

Supplementary Materials: The following are available online at https:/ / www.mdpi.com/article/10 $.3390 /$ v13040612/s1, Figure S1: Extended phylogeny of Phage A1 to streptococcal phages based on whole genomes; Figure S2: Growth curves of WT ATCC 12202 (left), WT SF370 (right) compared to three potential Phage A1 lysogens each; Figure S3: (A) Phage A1 plaquing on SF370 in the absence and presence of hyaluronidase in growth medium. Mean values \pm SD from three independent experiments are shown. (B) Alignment of acquired spacer sequences in WT SF370 (top) or SF370 $\triangle$ has $A$ (bottom) phage survivors to the Phage A1 genome highlighted in red on the dark yellow bar, marked by asterisks.

Author Contributions: Conceptualization, D.B.; methodology, investigation and analysis, D.B., S.F.-A., T.J.S., C.G., V.B.; writing-original draft preparation, D.B.; writing-review and editing, D.B, S.F.-A., T.J.S., C.G., V.B., E.C.; visualization, D.B, S.F.-A.; funding acquisition, E.C. All authors have read and agreed to the published version of the manuscript.

Funding: This work was supported by the Max Planck Society (to EC), the German Research Foundation (DFG, Leibniz Prize to EC) and the Tang Prize Foundation (Tang Prize to EC).

Institutional Review Board Statement: Not applicable.

Informed Consent Statement: Not applicable.

Data Availability Statement: Not applicable.

Acknowledgments: We would like to acknowledge Stefan Börno and Bernd Timmermann from the Max Planck Institute for Molecular Genetics for the sequencing of the Phage A1 genome.

Conflicts of Interest: The authors declare no conflict of interest.

\section{References}

1. Ferretti, J.; Köhler, W. History of Streptococcal Research; University of Oklahoma Health Sciences Center: Oklahoma City, OK, USA, 2016.

2. Vela, A.I.; Villalón, P.; Sáez-Nieto, J.A.; Chacon, G.; Dominguez, L.; Fernández-Garayzábal, J.F. Characterization of Streptococcus pyogenes from Animal Clinical Specimens, Spain. Emerg. Infect. Dis. 2017, 23, 2013-2016. [CrossRef]

3. Martin, J. The Streptococcus pyogenes Carrier State; University of Oklahoma Health Sciences Center: Oklahoma City, OK, USA, 2016.

4. Cunningham, M.W. Pathogenesis of group a streptococcal infections. Clin. Microbiol. Rev. 2000, 13, 470-511. [CrossRef]

5. Henningham, A.; Barnett, T.C.; Maamary, P.G.; Walker, M.J. Pathogenesis of group A streptococcal infections. Discov. Med. 2012, 13, 329-342.

6. Carapetis, J.R.; Steer, A.C.; Mulholland, E.K.; Weber, M. The global burden of group A streptococcal diseases. Lancet Infect. Dis. 2005, 5, 685-694. [CrossRef]

7. Cattoir, V. Mechanisms of Antibiotic Resistance. In Virulence Mechanisms of Bacterial Pathogens; American Society for Microbiology: Washington, DC, USA, 2016; pp. 481-511.

8. Brook, I. Penicillin Failure in the Treatment of Streptococcal Pharyngo-Tonsillitis. Curr. Infect. Dis. Rep. 2013, 15, 232-235. [CrossRef] [PubMed]

9. Cisek, A.A.; Dabrowska, I.; Gregorczyk, K.P.; Wyżewski, Z. Phage Therapy in Bacterial Infections Treatment: One Hundred Years After the Discovery of Bacteriophages. Curr. Microbiol. 2017, 74, 277-283. [CrossRef] [PubMed]

10. Koskella, B.; Meaden, S. Understanding Bacteriophage Specificity in Natural Microbial Communities. Viruses 2013, 5, 806-823. [CrossRef] [PubMed]

11. Fischetti, V.A. Streptococcal M protein: Molecular design and biological behavior. Clin. Microbiol. Rev. 1989, 2, 285-314. [CrossRef]

12. Maxted, W.R. The indirect bactericidal test as a means of identifying antibody to the M antigen of Streptococcus pyogenes. Br. J. Exp. Pathol. 1956, 37, 415-422. [PubMed] 
13. Perez-Casal, J.; Caparon, M.; Scott, J. Introduction of the emm6 gene into an emm-deleted strain of Streptococcus pyogenes restores its ability to resist phagocytosis. Res. Microbiol. 1992, 143, 549-558. [CrossRef]

14. Cleary, P.P.; Johnson, Z. Possible dual function of M protein: Resistance to bacteriophage A25 and resistance to phagocytosis by human leukocytes. Infect. Immun. 1977, 16, 280-292. [CrossRef]

15. Wessels, M.R. Cell Wall and Surface Molecules: Capsule; University of Oklahoma Health Sciences Center: Oklahoma City, OK, USA, 2016.

16. Ashbaugh, C.D.; Warren, H.B.; Carey, V.J.; Wessels, M.R. Molecular analysis of the role of the group A streptococcal cysteine protease, hyaluronic acid capsule, and M protein in a murine model of human invasive soft-tissue infection. J. Clin. Investig. 1998, 102, 550-560. [CrossRef] [PubMed]

17. Wessels, M.R.; Moses, A.E.; Goldberg, J.B.; Dicesare, T.J. Hyaluronic acid capsule is a virulence factor for mucoid group A streptococci. Proc. Natl. Acad. Sci. USA 1991, 88, 8317-8321. [CrossRef]

18. Maxted, W.R. Enhancement of Streptococcal Bacteriophage Lysis by Hyaluronidase. Nat. Cell Biol. 1952, 170, 1020-1021. [CrossRef]

19. DeAngelis, P.; Papaconstantinou, J.; Weigel, P. Isolation of a Streptococcus pyogenes gene locus that directs hyaluronan biosynthesis in acapsular mutants and in heterologous bacteria. J. Biol. Chem. 1993, 268, 14568-14571. [CrossRef]

20. Dougherty, B.A.; Van De Rijn, I. Molecular characterization of has A from an operon required for hyaluronic acid synthesis in group A streptococci. J. Biol. Chem. 1994, 269, 169-175. [CrossRef]

21. Heath, A.; DiRita, V.J.; Barg, N.L.; Engleberg, N.C. A Two-Component Regulatory System, CsrR-CsrS, Represses Expression of Three Streptococcus pyogenes Virulence Factors, Hyaluronic Acid Capsule, Streptolysin S, and Pyrogenic Exotoxin B. Infect. Immun. 1999, 67, 5298-5305. [CrossRef]

22. Fiebig, A.; Loof, T.G.; Babbar, A.; Itzek, A.; Koehorst, J.J.; Schaap, P.J.; Nitsche-Schmitz, D.P. Comparative Genomics of Streptococcus pyogenes M1 isolates differing in virulence and propensity to cause systemic infection in mice. Int. J. Med Microbiol. 2015, 305, 532-543. [CrossRef]

23. McShan, W.M.; McCullor, K.A.; Nguyen, S.V. The Bacteriophages of Streptococcus pyogenes. Microbiol. Spectr. 2019, 7, 158-176. [CrossRef] [PubMed]

24. Maxted, B.W.R. The Influence of Bacteriophage on Streptococcus pyogenes. Microbiology 1955, 12, 484-495. [CrossRef]

25. Wannamaker, L.W.; Almquist, S.; Skjold, S. Intergroup phage reactions and transduction between group C and group A streptococci. J. Exp. Med. 1973, 137, 1338-1353. [CrossRef] [PubMed]

26. Malke, H. Characteristics of transducing group A streptococcal bacteriophages A5 and A25. Arch. Virol. 1970, 29, 44-49. [CrossRef]

27. Malke, H. Transduction of Streptococcus pyogenes K 56 by Temperature-Sensitive Mutants of the Transducing Phage A25. Z. Nat. B 1969, 24, 1556-1561. [CrossRef]

28. Fischetti, V.A.; Barron, B.A.; Zabriskie, J.B. Studies on streptococcal bacteriophages. J. Exp. Med. 1968, 127, 475-488. [CrossRef] [PubMed]

29. Cleary, P.P.; Wannamaker, L.W.; Fisher, M.; Laible, N. Studies of the receptor for phage A25 in group A streptococci: The role of peptidoglycan in reversible adsorption. J. Exp. Med. 1977, 145, 578-593. [CrossRef] [PubMed]

30. McCullor, K.; Postoak, B.; Rahman, M.; King, C.; McShan, W.M. Genomic Sequencing of High-Efficiency Transducing Streptococcal Bacteriophage A25: Consequences of Escape from Lysogeny. J. Bacteriol. 2018, 200, e00358-18. [CrossRef]

31. Ferretti, J.J.; McShan, W.M.; Ajdic, D.; Savic, D.J.; Savic, G.; Lyon, K.; Primeaux, C.; Sezate, S.; Suvorov, A.N.; Kenton, S.; et al Complete genome sequence of an M1 strain of Streptococcus pyogenes. Proc. Natl. Acad. Sci. USA 2001, 98, 4658-4663. [CrossRef]

32. Abbot, E.L.; Smith, W.D.; Siou, G.P.S.; Chiriboga, C.; Smith, R.J.; Wilson, J.A.; Hirst, B.H.; Kehoe, M.A. Pili mediate specific adhesion of Streptococcus pyogenes to human tonsil and skin. Cell. Microbiol. 2007, 9, 1822-1833. [CrossRef]

33. Kazmi, S.U.; Kansal, R.; Aziz, R.K.; Hooshdaran, M.; Norrby-Teglund, A.; Low, D.E.; Halim, A.-B.; Kotb, M. Reciprocal, Temporal Expression of SpeA and SpeB by Invasive M1T1 Group A Streptococcal Isolates In Vivo. Infect. Immun. 2001, 69, 4988-4995. [CrossRef]

34. Aziz, R.K.; Pabst, M.J.; Jeng, A.; Kansal, R.; Low, D.E.; Nizet, V.; Kotb, M. Invasive M1T1 group A Streptococcus undergoes a phase-shift in vivo to prevent proteolytic degradation of multiple virulence factors by SpeB. Mol. Microbiol. 2003, 51, 123-134. [CrossRef] [PubMed]

35. Resch, U.; Tsatsaronis, J.A.; Le Rhun, A.; Stuebiger, G.; Rohde, M.; Kasvandik, S.; Holzmeister, S.; Tinnefeld, P.; Wai, S.N.; Charpentier, E. A Two-Component Regulatory System Impacts Extracellular Membrane-Derived Vesicle Production in Group A Streptococcus. mBio 2016, 7, e00207-16. [CrossRef]

36. Kropinski, A.M. Practical Advice on the One-Step Growth Curve. In Methods in Molecular Biology; Springer Science and Business Media LLC: Berlin, Germany, 2018; Volume 1681, pp. 41-47.

37. Bolger, A.M.; Lohse, M.; Usadel, B. Trimmomatic: A flexible trimmer for Illumina sequence data. Bioinformatics 2014, 30, 2114-2120. [CrossRef]

38. Bankevich, A.; Nurk, S.; Antipov, D.; Gurevich, A.A.; Dvorkin, M.; Kulikov, A.S.; Lesin, V.M.; Nikolenko, S.I.; Pham, S.; Prjibelski, A.D.; et al. SPAdes: A New Genome Assembly Algorithm and Its Applications to Single-Cell Sequencing. J. Comput. Biol. 2012, 19, 455-477. [CrossRef]

39. Seemann, T. Prokka: Rapid Prokaryotic Genome Annotation. Bioinformatics 2014, 30, 2068-2069. [CrossRef] [PubMed]

40. Meier-Kolthoff, J.P.; Göker, M. VICTOR: Genome-based phylogeny and classification of prokaryotic viruses. Bioinformations 2017, 33, 3396-3404. [CrossRef] [PubMed] 
41. Rapino, F.; Robles, E.F.; Richter-Larrea, J.A.; Kallin, E.M.; Martinez-Climent, J.A.; Graf, T. C/EBP $\alpha$ Induces Highly Efficient Macrophage Transdifferentiation of B Lymphoma and Leukemia Cell Lines and Impairs Their Tumorigenicity. Cell Rep. 2013, 3, 1153-1163. [CrossRef]

42. Athukoralage, J.S.; McMahon, S.A.; Zhang, C.; Grüschow, S.; Graham, S.; Krupovic, M.; Whitaker, R.J.; Gloster, T.M.; White, M.F. An anti-CRISPR viral ring nuclease subverts type III CRISPR immunity. Nat. Cell Biol. 2020, 577, 572-575. [CrossRef]

43. Dale, D.C.; Boxer, L.; Liles, W.C. The phagocytes: Neutrophils and monocytes. Blood 2008, 112, 935-945. [CrossRef] [PubMed]

44. Banks, D.J.; Porcella, S.F.; Barbian, K.D.; Martin, J.M.; Musser, J.M. Structure and Distribution of an Unusual Chimeric Genetic Element Encoding Macrolide Resistance in Phylogenetically Diverse Clones of Group A Streptococcus. J. Infect. Dis. 2003, 188, 1898-1908. [CrossRef] [PubMed]

45. Alberti, S.; Ashbaugh, C.D.; Wessels, M.R. Structure of the has operon promoter and regulation of hyaluronic acid capsule expression in group A Streptococcus. Mol. Microbiol. 1998, 28, 343-353. [CrossRef]

46. Graham, M.R.; Smoot, L.M.; Migliaccio, C.A.L.; Virtaneva, K.; Sturdevant, D.E.; Porcella, S.F.; Federle, M.J.; Adams, G.J.; Scott, J.R.; Musser, J.M. Virulence control in group A Streptococcus by a two-component gene regulatory system: Global expression profiling and in vivo infection modeling. Proc. Natl. Acad. Sci. USA 2002, 99, 13855-13860. [CrossRef]

47. Heler, R.; Samai, P.; Modell, J.W.; Weiner, C.; Goldberg, G.W.; Bikard, D.; Marraffini, L.A. Cas9 specifies functional viral targets during CRISPR-Cas adaptation. Nat. Cell Biol. 2015, 519, 199-202. [CrossRef] [PubMed]

48. Manning, A.J.; Kuehn, M.J. Contribution of bacterial outer membrane vesicles to innate bacterial defense. BMC Microbiol. 2011, 11, 258. [CrossRef]

49. Dunne, M.; Hupfeld, M.; Klumpp, J.; Loessner, M.J. Molecular Basis of Bacterial Host Interactions by Gram-Positive Targeting Bacteriophages. Viruses 2018, 10, 397. [CrossRef] [PubMed]

50. Harhala, M.; Barylski, J.; Humińska-Lisowska, K.; Lecion, D.; Wojciechowicz, J.; Lahutta, K.; Kuś, M.; Kropinski, A.M.; Nowak, S.; Nowicki, G.; et al. Two novel temperate bacteriophages infecting Streptococcus pyogenes: Their genomes, morphology and stability. PLoS ONE 2018, 13, e0205995. [CrossRef]

51. Broussard, G.W.; Oldfield, L.M.; Villanueva, V.M.; Lunt, B.L.; Shine, E.E.; Hatfull, G.F. Integration-Dependent Bacteriophage Immunity Provides Insights into the Evolution of Genetic Switches. Mol. Cell 2013, 49, 237-248. [CrossRef] [PubMed]

52. Kaplan, E.L.; Wotton, J.T.; Johnson, D.R. Dynamic epidemiology of group A streptococcal serotypes associated with pharyngitis. Lancet 2001, 358, 1334-1337. [CrossRef]

53. Ikebe, T.; Wada, A.; Inagaki, Y.; Sugama, K.; Suzuki, R.; Tanaka, D.; Tamaru, A.; Fujinaga, Y.; Abe, Y.; Shimizu, Y.; et al. Dissemination of the Phage-Associated Novel Superantigen Gene speL in Recent Invasive and Noninvasive Streptococcus pyogenes M3/T3 Isolates in Japan. Infect. Immun. 2002, 70, 3227-3233. [CrossRef]

54. Banks, D.J.; Lei, B.; Musser, J.M. Prophage Induction and Expression of Prophage-EncodedVirulence Factors in Group A Streptococcus Serotype M3 StrainMGAS315. Infect. Immun. 2003, 71, 7079-7086. [CrossRef]

55. Bondy-Denomy, J.; Qian, J.; Westra, E.R.; Buckling, A.; Guttman, D.S.; Davidson, A.R.; Maxwell, K.L. Prophages mediate defense against phage infection through diverse mechanisms. ISME J. 2016, 10, 2854-2866. [CrossRef]

56. Vojtek, I.; Pirzada, Z.A.; Henriques-Normark, B.; Mastny, M.; Janapatla, R.P.; Charpentier, E. Lysogenic Transfer of Group AStreptococcusSuperantigen Gene among Streptococci. J. Infect. Dis. 2008, 197, 225-234. [CrossRef]

57. Weeks, C.R.; Ferretti, J.J. The gene for type a streptococcal exotoxin (erythrogenic toxin) is located in bacteriophage T12. Infect. Immun. 1984, 46, 531-536. [CrossRef]

58. Monteiro, R.; Pires, D.P.; Costa, A.R.; Azeredo, J. Phage Therapy: Going Temperate? Trends Microbiol. 2019, 27, 368-378. [CrossRef] [PubMed]

59. Park, J.Y.; Moon, B.Y.; Park, J.W.; Thornton, J.A.; Park, Y.H.; Seo, K.S. Genetic engineering of a temperate phage-based delivery system for CRISPR/Cas9 antimicrobials against Staphylococcus aureus. Sci. Rep. 2017, 7, srep44929. [CrossRef] [PubMed]

60. Fischetti, V.A. Development of Phage Lysins as Novel Therapeutics: A Historical Perspective. Viruses 2018, 10, 310. [CrossRef]

61. Dugar, G.; Herbig, A.; Förstner, K.U.; Heidrich, N.; Reinhardt, R.; Nieselt, K.; Sharma, C.M. High-Resolution Transcriptome Maps Reveal Strain-Specific Regulatory Features of Multiple Campylobacter jejuni Isolates. PLoS Genet. 2013, 9, e1003495. [CrossRef] [PubMed]

62. Dugar, G.; Leenay, R.T.; Eisenbart, S.K.; Bischler, T.; Aul, B.U.; Beisel, C.L.; Sharma, C.M. CRISPR RNA-Dependent Binding and Cleavage of Endogenous RNAs by the Campylobacter jejuni Cas9. Mol. Cell 2018, 69, 893-905.e7. [CrossRef]

63. Sacher, J.C.; Flint, A.; Butcher, J.; Blasdel, B.; Reynolds, H.M.; Lavigne, R.; Stintzi, A.; Szymanski, C.M. Transcriptomic Analysis of the Campylobacter jejuni Response to T4-Like Phage NCTC 12673 Infection. Viruses 2018, 10, 332. [CrossRef]

64. Heler, R.; Wright, A.V.; Vucelja, M.; Doudna, J.A.; Marraffini, L.A. Spacer Acquisition Rates Determine the Immunological Diversity of the Type II CRISPR-Cas Immune Response. Cell Host Microbe 2019, 25, 242-249.e3. [CrossRef] [PubMed]

65. Nuñez, J.K.; Bai, L.; Harrington, L.B.; Hinder, T.L.; Doudna, J.A. CRISPR Immunological Memory Requires a Host Factor for Specificity. Mol. Cell 2016, 62, 824-833. [CrossRef]

66. Tsatsaronis, J.A.; Franch-Arroyo, S.; Resch, U.; Charpentier, E. Extracellular Vesicle RNA: A Universal Mediator of Microbial Communication? Trends Microbiol. 2018, 26, 401-410. [CrossRef] [PubMed]

67. Reyes-Robles, T.; Dillard, R.S.; Cairns, L.S.; Silva-Valenzuela, C.A.; Housman, M.; Ali, A.; Wright, E.R.; Camilli, A. Vibrio cholerae Outer Membrane Vesicles Inhibit Bacteriophage Infection. J. Bacteriol. 2018, 200. [CrossRef] [PubMed] 